\title{
New Simple Sequence Repeat Markers on Linkage Groups 2 and 7, and Investigation of New Sources of Eastern Filbert Blight Resistance in Hazelnut
}

\author{
Merve Şekerli, Golnaz Komaei Koma, Jacob W. Snelling, and Shawn A. Mehlenbacher \\ Department of Horticulture, Oregon State University, Corvallis, OR 97331
}

\begin{abstract}
AdDitional INDEX words. Anisogramma anomala, Corylus avellana, disease resistance, linkage mapping, microsatellite, tree breeding

Abstract. Eastern filbert blight (EFB), caused by Anisogramma anomala, is a fungal disease threatening the european hazelnut (Corylus avellana) industry in the Willamette Valley of Oregon. The pathogen is endemic to the eastern United States where it causes little damage to the wild Corylus americana but causes severe cankers on most cultivars of the commercially important european hazelnut. The host genetic resistance in 'Gasaway' is conferred by a dominant allele at a single locus on linkage group 6 (LG6), and resistance from several other sources has been mapped to the same region. Some fungal isolates can overcome 'Gasaway' resistance, prompting a search for other sources of resistance. Resistance from other sources has been mapped to LG2 and LG7, for which additional simple sequence repeat (SSR) markers would facilitate marker-assisted selection (MAS). In this study, an in silico approach was used to develop new polymorphic SSR markers in the EFB resistance regions on LG2 and LG7. Starting with a search of 17 contigs of the 'Jefferson' genome sequence, 45 new polymorphic SSR markers were developed, characterized, and placed on the linkage map. The new SSR markers had an average of $\mathbf{1 0 . 1 8}$ alleles per locus, and average values for expected heterozygosity, observed heterozygosity, polymorphism information content, and frequency of null alleles of $0.72,0.65,0.68$, and 0.068 , respectively. Of the 42 new polymorphic SSRs segregating in the mapping population, 24 were on LG2, 12 were on LG7, and six were placed on other LGs. The new and previously developed SSR markers were used to study six new sources of EFB resistance, four from Russia and two from Crimea. Six resistant selections were crossed with susceptible selections, resulting in 7 progenies. Phenotyping for disease response revealed that segregation in progenies of the two Moscow selections (\#2 and \#27), one Russian selection (OSU 1187.101), and one Crimean selection (H3R12P62) fit the 1:1 segregation ratio expected for control of resistance by a dominant allele at a single locus; but in progenies of the other Russian selection (OSU 1166.123) and the other Crimean selection (H3R07P11), there was an excess of resistant seedlings. Correlation of disease scores and alleles at SSR loci indicated that resistance from three Russian selections (Moscow selections \#2 and \#27 and OSU 1166.123) and the Crimean selection H3R12P62 was on LG7, while resistance from Russian selection OSU 1187.101 was on LG2. Resistance from Crimean selection H3R07P11 was not correlated with markers on LG6, or LG2, or LG7. These sources and new SSR markers will be useful in MAS and the pyramiding of resistance genes in the breeding of new EFB-resistant cultivars.
\end{abstract}

European hazelnut (Corylus avellana), also known as filbert, is an economically important nut crop. Hazelnuts are consumed as whole kernels or used as ingredients by the food industry. Hazelnut oil can also be used as cooking oil and for biofuel.

Received for Publication 7 Jan. 2021. Accepted for Publication 14 Feb. 2021.

Published online 11 May 2021.

This research was supported by the Oregon Hazelnut Commission, the Oregon Agricultural Experiment Station, U.S. Department of Agriculture (USDA)-National Institute of Food and Agriculture (NIFA) Specialty Crops Research Initiative Competitive Grant 2016-51181-25412, USDA-NIFA Agriculture and Food Research Initiative Competitive Grant 2014-67013-22421, and a USDA Specific Cooperative Agreement for Eastern Filbert Blight Research.

We thank Senior Research Assistants David C. Smith and Rebecca L. McCluskey for managing the plant material and for assistance with disease data collection. We appreciate the help of Kelly Vining, who provided the 'Jefferson' hazelnut genome sequences (V2 and V3) used in this study.This research partially fulfilled the requirements for M. Sekerli's Master of Science degree and G. Komaei Koma's Doctor of Philosophy degree.

M.S. and G.K.K. are Former Graduate Research Assistants.

J.W.S. is a Faculty Research Assistant.

S.A.M. is a Professor.

S.A.M. is the corresponding author. E-mail: Shawn.Mehlenbacher@oregonstate.edu. This is an open access article distributed under the CC BY-NC-ND license (https://creativecommons.org/licenses/by-nc-nd/4.0/).
Hazelnuts are highly nutritious and provide unsaturated fatty acids, diet-friendly fiber, protein, vitamins, and antioxidants. Additionally, a balanced intake of hazelnuts reduces the risk of cardiovascular disease (Ramalhosa et al., 2011). Ninety-nine percent of the U.S. hazelnut production is in the Willamette Valley of Oregon [U.S. Department of Agriculture (USDA)-National Agricultural Statistics Service (NASS), 2018]. The acreage has increased rapidly in the past decade as orchards of new cultivars from Oregon State University (OSU) have been planted.

Eastern filbert blight (EFB), caused by the pathogen Anisogramma anomala, is the most destructive disease of hazelnut in Oregon. The pathogen is endemic to eastern North America, where it occasionally causes small cankers on selections of the native C. americana (Capik and Molnar, 2012). However, the fungus causes severe infections on most cultivars of european hazelnut (Pinkerton et al., 1993), and it was first reported in the Pacific Northwest United States in 1970 (Davison and Davidson, 1973). The causal agent is an obligate, biotrophic ascomycete with a 2-year life cycle. The disease cycle and symptoms were described by Stone et al. (1992), Pinkerton et al. (1992, 1995, 1998, 2001), and Johnson et al. (1994, 1996). The cycle begins when stromata in cankers become wet in the spring, and ascospores are disseminated by wind and rain. These spores infect 
young shoots and breaking buds (Pscheidt, 2010). Cankers with stromata become visible 12 to 16 months after infection. The cankers expand each year, producing new stromata, ultimately causing dieback and death of susceptible plants in 5 to 12 years in the absence of fungicides (Pinkerton et al., 1993). EFB control measures include scouting for cankers, pruning of infected wood, and regular fungicide applications (Johnson et al., 1994; Pscheidt, 2010). These cultural practices delay disease spread but are expensive. The development and planting of EFB-resistant cultivars is considered the most cost-effective and environmentally friendly control method (Mehlenbacher, 1995).

There are two classes of host genetic resistance. Quantitative resistance reduces the severity of the disease, while qualitative resistance is usually a high level of resistance conferred by a dominant allele at a single locus. Most qualitative resistance genes (R-genes) follow the gene-for-gene model first proposed by Flor (1942). Resistance genes in various plants have been placed in categories based on their similar DNA sequences. The most represented group of R-genes has a nucleotide-binding domain (NB) and a leucine-rich repeat (LRR) domain (Hulbert et al., 2001; McHale et al., 2006). In hazelnut, 115 putative NBLRR proteins were annotated in the version 1 (V1) genome sequence of 'Jefferson' produced by sequencing using Illumina (San Diego, CA) technology (Rowley et al., 2018).

The hazelnut breeding programs at OSU and Rutgers University have identified more than 150 accessions that exhibit a very high level of EFB resistance (S.A. Mehlenbacher and T.J. Molnar, unpublished data). 'Gasaway', a late-blooming pollinizer, was the first $C$. avellana identified with very high resistance to EFB (Cameron, 1976). The resistance of 'Gasaway' is controlled by a dominant allele at a single locus (Mehlenbacher et al., 1991) that was placed on linkage group 6 [LG6 (Mehlenbacher et al., 2006)]. Grower selection 'Zimmerman' also has a high level of resistance (Lunde et al., 2006). Simple sequence repeat (SSR) markers, also known as microsatellites, indicate that 'Zimmerman' is from a cross of 'Barcelona' and 'Gasaway' (Gökirmak et al., 2009) and thus is the same source of resistance. The OSU hazelnut breeding program has extensively used 'Gasaway' resistance and recent releases, including 'Yamhill', 'Jefferson', 'Dorris', 'Wepster', 'McDonald', and 'PollyO' (Mehlenbacher et al., 2009, 2011, 2013, 2014, 2016, 2019); and the pollinizers 'Gamma', 'Epsilon', 'Theta', 'York', and 'Felix' (Mehlenbacher and Smith, 2004; Mehlenbacher et al., 2012, 2018) carry this resistance. Sathuvalli et al. (2017) fine mapped and predicted genes in the EFB resistance region in 'Jefferson'.

Additional sources of EFB resistance have been identified and assigned to LGs. Resistance in OSU 408.040 from Minnesota (Sathuvalli et al., 2012), OSU 495.072 from Russia, 'Culpla' from Spain, and 'Crvenje' and 'Uebov' from Serbia (Bhattarai et al., 2017a; Colburn et al., 2015) was assigned to LG6. Resistance in 'Ratoli' from Spain (Sathuvalli et al., 2011a), C. americana 'Rush', and interspecific hybrid 'Yoder \#5' (Bhattarai et al., 2017b) was assigned to LG7. Resistance from OSU 759.010 from the Republic of Georgia and Rutgers University selection H3R07P25 from Holmskij, Russia was assigned to LG2 (Honig et al., 2019; Sathuvalli et al., 2011b). Sathuvalli et al. (2010) reported that Moscow selections \#2 and \#27 were EFB resistant following greenhouse inoculation. Additional resistant selections have been identified in germplasm collected in Russia, Crimea, and Poland (Capik et al., 2013; Molnar et al., 2007). Two selections from seeds purchased in Crimea,
H3R7P11 and H3R12P62, were included in the germplasm characterization study of Muehlbauer et al. (2014). These two Rutgers University selections were inoculated with the EFB pathogen in the greenhouse and field and found to be resistant (Capik et al., 2013; Molnar et al., 2007). At OSU, potted trees of two additional selections of Russian origin, OSU 1166.123 from seeds collected in Sochi and OSU 1187.101 from seeds purchased in a market in Holmskij, remained free of EFB following exposure under a structure topped with diseased wood in 2014 and 2013, respectively. Subsequent greenhouse inoculation at OSU confirmed their resistance. In New Jersey, OSU 1166.123 remained free of disease signs and symptoms (Leadbetter et al., 2016).

The long-term durability of a single source of EFB resistance is a concern of the Oregon hazelnut industry (Lunde et al., 2006; Molnar et al., 2010a), especially as cultivars with Gasaway resistance have been extensively planted in the Willamette Valley in the past decade. Small cankers have been observed on OSU releases, including 'Jefferson' and 'McDonald', under high disease pressure (Pscheidt and Ocamb, 2020). Molnar et al. (2010b) and Capik and Molnar (2012) demonstrated pathogenic variation in A. anomala, with isolates from New Jersey and Michigan able to infect 'Gasaway' and its offspring. The use of multiple sources of resistance and the pyramiding of two or more R-genes in a single host genotype are approaches to reduce the likelihood of the pathogen overcoming resistance.

Mehlenbacher et al. (2006) constructed the first genetic linkage map for hazelnut using random amplified polymorphic DNA (RAPD) and SSR markers. More than 700 polymorphic SSR markers have been developed in C. avellana (Bassil et al., 2005a, 2005b, 2013; Bhattarai and Mehlenbacher, 2017, 2018; Boccacci et al., 2005, 2015; Colburn et al., 2017; Gürcan and Mehlenbacher, 2010a; Gürcan et al., 2010), of which $\approx 450$ have been placed on the reference linkage map (Mehlenbacher and Bhattarai, 2018). The reference map revealed segregation distortion at loci on LG2 and LG7 and the merger of the two linkage groups in the map of the male parent (Mehlenbacher and Bhattarai, 2018; Mehlenbacher et al., 2006). This was attributed to a reciprocal translocation involving LG2 and LG7 (Komaei Koma, 2020; Salesses, 1973; Salesses and Bonnet, 1988). Komaei Koma (2020) used bioinformatic methods to disentangle the "pseudo-linkage" of markers on LG2 and LG7 in the male parent (OSU 414.062).

Rowley et al. (2018) used Illumina short-read sequencing to generate the first genome sequence $(93 \times)$ for Jefferson hazelnut, which was chosen as the reference cultivar. More recently, the 'Jefferson' genome was sequenced using long reads from the Pacific Biosciences (PacBio, Menlo Park, CA) RSII sequencer providing $\approx 49 \times$ coverage (Snelling et al., 2018). The resulting contigs were error-corrected using the Illumina reads of Rowley et al. (2018) and constituted the version 2 (V2) reference genome for 'Jefferson'. The error-corrected PacBio reads were assembled into chromosome-level scaffolds using Hi-C proximity ligation procedures (Dovetail Genomics, Scotts Valley, CA). The resulting 11 scaffolds correspond to the haploid chromosome number of hazelnut $(2 n=2 x=22)$ and represent the V3 genome sequence of 'Jefferson'. The V3 genome (V3) shows two separate scaffolds for LG2 and LG7. The coordinates of SSR markers on the two scaffolds have been identified. 
Table 1. Hazelnut accessions used for characterization of 45 new polymorphic simple sequence repeat markers from genome sequences. Accessions 1 to 24 were used to screen for polymorphism on agarose gels, while all 50 accessions were used for characterization of the new markers. The country and region of origin, as well as the source of scions or seed, are shown for each. Some accessions were imported as scions, and others as seed lots from which individuals were selected. Plant Inventory (PI) numbers are provided for accessions from the USDA-ARS National Clonal Germplasm Repository collection.

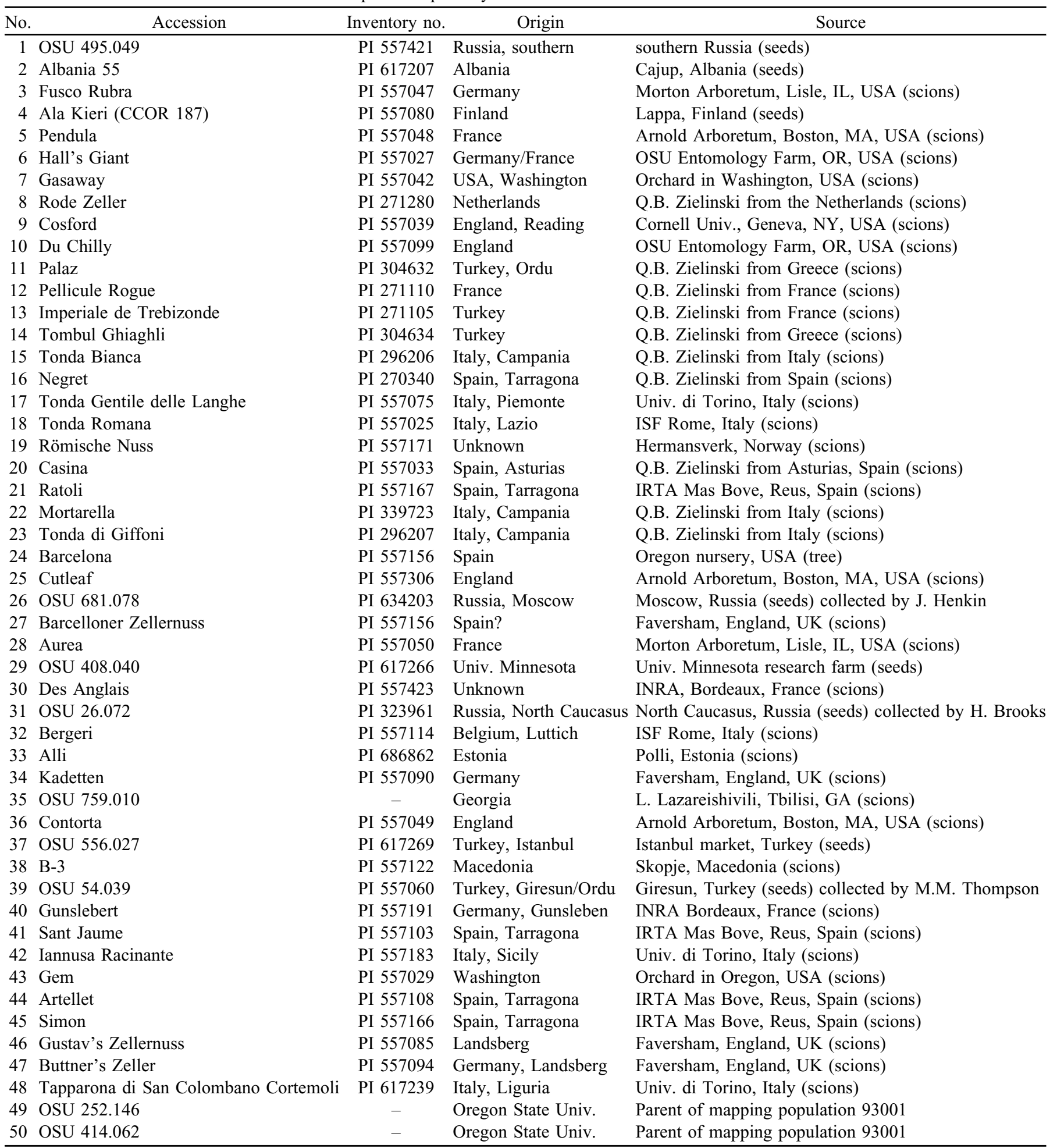

The objectives of this study were to develop new SSR markers in the EFB resistance regions on LG2 and LG7 and to investigate EFB resistance from six new sources, four of Russian and two of Crimean origin.

\section{Materials and Methods}

Plant materials for marker development. To validate polymorphism on agarose gels, a set of 24 diverse european 
hazelnut accessions was used (Table 1 ). These 24 , an additional 24 hazelnut accessions, and the two parents of the reference mapping population (OSU 252.146 and OSU 414.062) were used to characterize the new SSR markers (Table 1). These accessions were investigated by Gökirmak et al. (2009) and chosen to represent the genetic diversity in the $C$. avellana germplasm collection. This set of 50 diverse accessions was previously used in numerous SSR marker characterization studies (Bhattarai and Mehlenbacher, 2017, 2018; Colburn et al., 2017; Gürcan and Mehlenbacher, 2010a; Gürcan et al., 2010). To map the SSR markers, we used 138 seedlings of the mapping population. While the female parent (OSU 252.146) is susceptible, the male parent (OSU 414.062) is resistant to EFB.

Plant materials for disease resistance studies. Six EFBresistant selections were crossed with EFB-susceptible selections over a 4-year period (2011-14), generating seven progenies that segregated for disease response and a total of 545 seedlings. Their pedigrees are shown in Supplemental Table 1. Selections Moscow \#2 and Moscow \#27 were imported as scions from the Russian Research Institute of Forestry and Mechanization in Pushkino, Moscow Province, Russian Federation; and four selections originated from imported seed lots. OSU 1187.101 was from seeds purchased in an outdoor market in the village of Holmskij, Russia (near Krasnodar); the lot was designated RUS10 by Molnar et al. (2007). OSU 1166.123 was from seeds collected at the Institute of Floriculture and Subtropical Cultures in Sochi, Russia; and two Rutgers University selections (H3R7P11 and H3R12P62) were from seeds purchased from roadside vendors near Simferopol, Crimea. The two Rutgers University selections were from seed lots designated RUS-26 and RUS-23, respectively, by Molnar et al. (2007) and Capik et al. (2013). The selection OSU 1166.123 was crossed in 2013 with susceptible parents OSU 1235.078 and OSU 1236.134, generating progenies 13030 and 13031, respectively.

DNA EXTRACTION. For SSR marker development and characterization, young leaves were collected from trees growing in the field at OSU's Smith Horticulture Research Farm and the USDA-Agricultural Research Service National Clonal Germplasm

Table 2. Contigs in the genome sequence (V2) of 'Jefferson' hazelnut pursued for simple sequence repeat marker development and the markers used to identify them.

\begin{tabular}{lll}
\hline Linkage group & Contig & Markers used for identification \\
\hline LG2 & $026 \mathrm{~F}$ & GB829, B005, B504 \\
$046 \mathrm{~F}$ & B509 \\
$107 \mathrm{~F}$ & KG852 \\
$113 \mathrm{~F}$ & B501 \\
$121 \mathrm{~F}$ & BR230 \\
$140 \mathrm{~F}$ & KG846, A024b \\
$229 \mathrm{~F}$ & GB329 \\
$230 \mathrm{~F}$ & GB609 \\
$266 \mathrm{~F}$ & KG852 \\
$284 \mathrm{~F}$ & GB329, GB609 \\
$061 \mathrm{~F}$ & BR238 \\
$046 \mathrm{~F}$ & GB467, B733, KG830, B753, KG830, B733, B509 \\
& $074 \mathrm{~F}$ & B730 \\
& $076 \mathrm{~F}$ & GB822, B020 \\
LG7 & B751 \\
& $126 \mathrm{~F}$ & GB482, GB372 \\
& GB822 \\
& 535F & B730 \\
\hline
\end{tabular}

Repository (NCGR) in Corvallis, OR. Total DNA was extracted from two to four fresh young leaves, as described by Lunde et al. (2000), without RNAase treatment. The quality and quantity of the DNA samples were assessed using a microplate reader (Synergy2; BioTek Instruments, Winooski, VT) paired with Gen5 data analysis software and adjusted to a concentration of $20 \mathrm{ng} \cdot \mu \mathrm{L}^{-1}$. For EFB resistance mapping, DNA was extracted from the parents and seedlings of the five progenies inoculated under the structure $(10015,11024,12030,14031$, and 14035) and the two progenies inoculated in the field (14030 and 14031). Fresh young leaves were collected from seedlings in the EFB nursery or seedling rows at the Smith Horticultural Research Farm in Corvallis, OR. DNA extraction procedures for the seedlings in progenies segregating for EFB response, and the 138 seedlings used for mapping, were the same as for the 50 accessions used for characterization.

Microsatellite marker identification. The DNA sequences of a set of previously developed SSR markers on LG2 and LG7 (Table 2) were aligned with the 'Jefferson' genome (V2) assembled from PacBio sequences (Snelling et al., 2018). In addition, 28 double digest restriction site associated DNA sequencing (ddRAD-Seq) markers with positions from 2.57 to $24.76 \mathrm{cM}$ on LG2 were aligned with the V2 'Jefferson' reference genome, of which RUCaS1_18603 and RUCaS1_14004 flanked the EFB resistance quantitative trait locus (QTL) in Rutgers University selection H3R07P25 from Holmskij, Russia (Honig et al., 2019). The alignment of the marker sequences with the V2 genome sequence identified contigs associated with the EFB resistance regions on these two LGs, and the contigs were mined for SSR motifs $>16$ bp using the GMATo program (Wang et al., 2013). The SSRs were placed in separate folders according to the length of the repeat motif: di-, tri-, tetra-, penta-, and hexa-nucleotide repeats. Of these, di-nucleotide repeats with at least eight repeat units were pursued for marker development. SSRs that contained only As and Ts were removed, because such markers were previously found to be difficult to score. The sequences were trimmed using Samtools (Li et al., 2009) to $500 \mathrm{bp}$ with the SSR in the center. The genomes of seven other $C$. avellana accessions ('Barcelona', 'Ratoli', 'Tonda Gentile delle Langhe', 'Tonda di Giffoni', 'Daviana', 'Hall's Giant', and 'Tombul') resequenced using Illumina HiSeq 2000 (Rowley et al., 2018) at $\approx 20 \times$ coverage were aligned with the V2 'Jefferson' sequence, and the aligned reads were visualized using Tablet software (Milne et al., 2010). Sequences with variation in the number of repeats (but with conserved flanking regions) were identified, and only SSRs that showed $\geq$ three alleles were chosen for further study. All sequences were analyzed for redundancy using the ClustalW program (Thompson et al., 2002), and duplicates were removed. Then, a BLAST search (Ye et al., 2006) was performed to identify and eliminate sequences containing SSRs that had been previously developed. Nonfluorescent forward and reverse primers were designed using Primer 3 software (Untergasser et al., 2012) 
with the following criteria: 1) expected length of the amplified fragment between 90 and $315 \mathrm{bp}$; 2) primer length between 19 and 23 bases; and 3 ) annealing temperature $60^{\circ} \mathrm{C}$. Primers were ordered from Integrated DNA Technologies (Coralville, IA).

INITIAL SCREENING OF MARKERS. Primer pairs were screened for polymorphism using a set of 24 C. avellana accessions (Table 1). PCRs were performed in $10 \mu \mathrm{L}$ final volumes with a mixture of $20 \mathrm{ng}$ DNA, $1 \times \mathrm{NH}_{4}$ reaction buffer, $2.5 \mathrm{~mm}$ mix dNTP, $2 \mathrm{~mm} \mathrm{MgCl}_{2}, 0.3 \mu \mathrm{L}$ of each forward and reverse primer $(10 \mu \mathrm{M})$, and 0.25 units of DNA polymerase (Biolase; Bioline USA, Taunton, MA). PCRs were performed in 96-well plates on thermal cyclers (GeneAmp PCR System 9700; Applied Biosystems, Foster City, CA). The amplification program consisted of an initial denaturation for $5 \mathrm{~min}$ at $94^{\circ} \mathrm{C}$, followed by 40 cycles of $40 \mathrm{~s}$ at $94^{\circ} \mathrm{C}, 40 \mathrm{~s}$ at the annealing temperature $\left(60\right.$ or $\left.62^{\circ} \mathrm{C}\right)$, $40 \mathrm{~s}$ for elongation at $72^{\circ} \mathrm{C}$, a final extension step of $7 \mathrm{~min}$ at $72{ }^{\circ} \mathrm{C}$, and then an infinite hold at $4{ }^{\circ} \mathrm{C}$. The PCR products were separated by electrophoresis on 3\% agarose gels in TBE buffer at $90 \mathrm{~V}$ for $3.5 \mathrm{~h}$, stained with ethidium bromide, destained in distilled water, and photographed under ultraviolet light using a BioDoc-It Imaging System (UVP, Upland, CA). The gel images were inspected for size polymorphism among the 24 accessions.

GENOTYPING WITH POLYMORPHIC SSRs. For each SSR primer pair showing clear polymorphism on agarose gels, a forward primer labeled at its 5 ' end with fluorescent dye FAM or HEX was ordered from Integrated DNA Technologies. DNA from 50 diverse accessions (Table 1) was amplified with the fluorescent forward primers and nonfluorescent reverse primers with the same PCR cocktail ingredients and amplification program used in the initial screening. Post-PCR multiplexing of products with different sizes and fluorescent tags allowed up to seven SSRs to be simultaneously separated by capillary electrophoresis. After PCR, products were multiplexed by mixing $2 \mu \mathrm{L}$ of each PCR product in water to a final volume of $200 \mu \mathrm{L}$, and an aliquot (1.8 $\mu \mathrm{L}$ ) was submitted to the Core Laboratories of OSU's Center for Genome Research and Biocomputing (CGRB) for fragment sizing by capillary electrophoresis on an ABI 3730 instrument using ROX-500 as the size standard. Allele sizes were visualized and scored with ABI GeneMapper software (Life Technologies, Carlsbad, CA), and sizes were recorded in a spreadsheet. Ease of scoring was also noted. If amplification failed, or the capillary electrophoresis output could not be scored with confidence, the PCR and sizing were repeated. Allele sizes in the seedling populations were determined in the same manner.

Marker Characterization. After capillary electrophoresis sizing, the data were used to calculate measures of genetic diversity. The number of alleles per locus, observed heterozygosity $\left(\mathrm{H}_{\mathrm{o}}\right)$, expected heterozygosity $\left(\mathrm{H}_{\mathrm{e}}\right)$, and the polymorphism information content (PIC) were estimated for each marker using PowerMarker software (Liu and Muse, 2005). Cervus software (Field Genetics, London, UK) was used to estimate null allele frequency $[F($ null) $]$, according to the maximum likelihood procedure of Kalinowski and Taper (2006). A null allele at an SSR locus consistently fails to amplify to detectable levels by PCR.

MaPPING OF POLYMORPhIC SSRs. Newly developed SSR markers were placed on the linkage map using 138 seedlings of the reference mapping population from the cross OSU 252.146 $\times$ OSU 414.062 (Mehlenbacher et al., 2006). A two-way pseudo-testcross approach (Grattapaglia and Sederoff, 1994) and JoinMap 5 (Kyazma, Wageningen, The Netherlands) were used with "BC1" as the population type, Kosambi as the mapping function, and a logarithm of the odds (LOD) threshold $\geq 6$ for grouping. Because of the merger of LG2 and LG7 in the previous maps of the male parent, only SSR markers were used for mapping; and the scaffolds and coordinates of new and previously developed SSR markers in the 'Jefferson' genome (V3) were consulted in map construction. Each SSR allele size was scored as present or absent in each seedling. Allele scores for the new SSR markers were combined with those for the previously mapped SSR markers on the two V3 genome scaffolds and imported into JoinMap 5 software. Linkage map construction was as described by Bhattarai and Mehlenbacher (2017), with a LOD score of 6 for grouping. Markers segregating in a ratio of 1:1 or 1:1:1:1 were scored as " $h$," "a," or " $u$ " for presence, absence, or unknown status, respectively, for each allele in each seedling. Similarly, markers segregating in a ratio of 1:2:1 were scored as " $\mathrm{h}$ " if present in homozygous state, "a" if absent (homozygous), and " $\mathrm{u}$ " if heterozygous or having an unknown status. At loci segregating in a 1:2:1 ratio, heterozygotes provide no information useful for mapping. Markers that clustered loosely with the others and fell out at LOD scores $<6$ were removed. Markers present in the repulsion phase were included in the map by creating "dummy variables," the use of which allowed the merger of the repulsion phase and coupling phase markers, and generation of a single map for each LG in each parent. The JoinMap output was inspected for "Fit and Stress," and markers were removed in stepwise manner until the "Nearest Neighbor Stress" value for all markers was less than an arbitrarily set value of 6.60 . The "Nearest Neighbor Fit (cM)" values were also inspected, as high values indicate blocks of markers that fit poorly with adjacent markers. In addition, the length of the gaps between markers was inspected, with gaps of $>20 \mathrm{cM}$ considered suspicious. Maps that included previously mapped RAPD markers were also constructed for LG2 and LG7 in the female parent for comparison with maps with only SSR markers. For marker loci not placed on LG2 or LG7, their scores were merged with those of previously mapped RAPD and SSR markers and maps constructed as described by Mehlenbacher and Bhattarai (2018).

STRuCture inoculations. Hybrid seeds from the crosses of the two Moscow selections, two Rutgers University selections, and OSU 1187.101 were harvested in late August, stratified, and planted in flats in the greenhouse as they germinated. When $\approx 30 \mathrm{~cm}$ tall, they were transplanted to $3-\mathrm{L}$ pots and grown in the greenhouse during the summer. Potted seedlings were placed under the EFB inoculation structure at the OSU Smith Horticulture Research Farm in the spring, about 2 years after the crosses were made. In this technique, diseased branches with stromata were placed on top of the wire mesh platform held over the seedlings, as described by Pinkerton et al. (1993). Cultivars with known levels of susceptibility were included as controls: Ennis (highly susceptible), Barcelona (intermediate), Lewis (moderate resistance), Sacajawea (high quantitative resistance), and Tonda di Giffoni (high quantitative resistance). After the EFB exposure, the trees were transplanted to nursery rows, and disease phenotypes were scored 18 months after inoculation. Seedlings were rated on a scale of 0 to 5 , with 0 being absence of disease symptoms and 5 being severe disease symptoms $[1=$ if sunken area without any stromata is smaller than $10 \mathrm{~cm} ; 2=$ small cankers $(<5 \mathrm{~cm})$ with few stromata; $3=$ cankers with mature stromata; $4=$ pustules are very common, covering up to $50 \%$ of the branch length; $5=$ pustules 
are also common over the tree, and shoot tips are dead]. For correlation and segregation analyses, plants scoring 0-2 were considered resistant, and 3-5 were considered susceptible.

Field inOCulations. For progenies 13030 and 13031 segregating for resistance from OSU 1166.123, the hybrid seeds and seedlings were handled as described previously for structure inoculation, but they were planted in the field without EFB inoculation in Oct. 2016 at a spacing of $0.9 \mathrm{~m}$ apart in rows $3.0 \mathrm{~m}$ apart. A total of 156 seedlings were planted in the field, where they were exposed to EFB spores from a nearby orchard. By Jan. 2018, cankers were noted on some seedlings, and those without cankers were pruned and given supplemental inoculation. If the seedling showed no disease, the small suckers at its base were removed with loppers or pruning shears, leaving $\approx 5$ $\mathrm{cm}$ at the base, while the main stem and two largest suckers remained uncut. The trimming of suckers was intended to stimulate new growth at the base and increase the likelihood of EFB infection in susceptible seedlings. Diseased branches with mature cankers were collected in Dec. 2017 from the OSU Smith Horticulture Research farm and stored in polyethylene bags at $-20^{\circ} \mathrm{C}$. In Mar. 2018, a single diseased branch $\approx 15 \mathrm{~cm}$ long was tied in the upper part of the tree before leaf budbreak, as described by Molnar et al. (2007), except that no wax was used to seal the ends of the twigs. Disease was scored in these seedlings as present or absent in Apr. 2019, and scores were verified in Aug. 2019.

Data analysis for disease ReSponse. Chi-square tests were performed to assess goodness-of-fit to a 1:1 segregation ratio in all progenies. For the two progenies of OSU 1166.123, a homogeneity chi-square test was used to determine if the data could be pooled.

SSR MARKER SCORING AND CORRELATION ANALYSIS. For correlation analysis, the disease response and alleles at SSR markers were scored in a set of 32 seedlings in progenies 10015, 11024, and 12030, while 46 seedlings and the two parents were used for the remaining four progenies (13030, 13031, 14031, and 14036). The DNA was amplified using PCR and primers for ten SSR markers previously placed on the linkage map (Table 3 ) in regions where EFB resistance had been mapped. Of the ten, three were on LG6 in the 'Gasaway' resistance region, four were on LG2 in the Georgian resistance region, and three were on LG7 in the 'Ratoli' resistance region. Disease ratings and allele sizes at each SSR marker for each seedling in each progeny were entered in a spreadsheet. Resistant seedlings were scored as 1, and susceptible seedlings were scored as 0 . Presence or absence of a marker allele was scored as 1 or 0 , respectively. Pearson product-moment correlation coefficients were calculated for scores of disease and presence of each SSR allele. If the absolute value of the correlation coefficient was $>0.5$, additional seedlings in the population and additional SSR markers on that LG were pursued.

Mapping Resistance LOCI. After the linkage group had been identified, primers of several SSR markers previously assigned to that linkage group were used to amplify the parents and seedlings of each progeny. The selected markers were easy to score and were located within $20 \mathrm{cM}$ of a previously mapped resistance locus. All seedlings were scored at SSR marker loci segregating on that LG. The SSR alleles of the seedlings were

Table 3. Correlation coefficients for eastern filbert blight disease scores and simple sequence repeat markers on three linkage groups in seven hazelnut progenies. New markers on linkage groups 2 and 7 have an MS prefix. Resistant parents are shown in bold.

\begin{tabular}{|c|c|c|c|c|c|c|c|c|}
\hline \multirow[b]{6}{*}{ Linkage group } & \multirow[b]{6}{*}{ Marker } & \multicolumn{7}{|c|}{ Progeny } \\
\hline & & 10015 & 11024 & 12030 & 13030 & 13031 & 14031 & 14035 \\
\hline & & \multicolumn{7}{|c|}{ Parents } \\
\hline & & $\begin{array}{c}\text { OSU } 1 \mathbf{1 8 7 . 1 0 1} \times \\
\text { OSU } 1155.049\end{array}$ & $\begin{array}{c}\text { OSU } 814.073 \times \\
\text { Moscow \#2 }\end{array}$ & $\begin{array}{c}\text { OSU } 1269.020 \times \\
\text { Moscow \#27 }\end{array}$ & $\begin{array}{c}\text { OSU } \mathbf{1 1 6 6 . 1 2 3} \times \\
\text { OSU } 1235.078\end{array}$ & $\begin{array}{c}\text { OSU } \mathbf{1 1 6 6 . 1 2 3} \times \\
\text { OSU } 1236.134\end{array}$ & $\begin{array}{c}\text { Sacajawea } \times \\
\text { H3R07P11 }\end{array}$ & $\begin{array}{c}\text { H3R12P62 } \times \\
\text { OSU } 1378.046\end{array}$ \\
\hline & & \multicolumn{7}{|c|}{ Seedlings (no.) } \\
\hline & & 32 & 32 & 32 & 46 & 46 & 46 & 46 \\
\hline 6 & GK6.63 & - & - & - & - & - & - & 0.11 \\
\hline 6 & GK6.81 & - & - & - & - & - & 0.16 & 0.15 \\
\hline 6 & LG682 & - & - & - & - & - & 0.03 & 0.11 \\
\hline 2 & B504 & 0.76 & 0.11 & 0.09 & - & - & - & - \\
\hline 2 & B509 & - & - & 0.15 & - & - & - & - \\
\hline 2 & B758 & 0.52 & - & - & 0.18 & 0.09 & - & 0.02 \\
\hline 2 & MS0026.04 & - & 0.05 & - & - & - & - & - \\
\hline 2 & MS0026.08 & 0.75 & 0.08 & - & 0.02 & 0.04 & 0.06 & 0.30 \\
\hline 2 & MS0026.10 & 0.72 & - & - & - & - & - & - \\
\hline 2 & MS0026.11 & 0.71 & 0.11 & - & - & - & - & - \\
\hline 2 & MS0026.14 & - & - & - & 0.09 & - & - & 0.24 \\
\hline 2 & MS0113.04 & 0.62 & - & - & 0.21 & 0.14 & 0.11 & - \\
\hline 7 & B020 & - & 0.88 & 0.78 & - & - & - & - \\
\hline 7 & B751 & - & 0.50 & 0.76 & - & - & - & - \\
\hline 7 & B753 & - & 0.90 & - & - & - & - & - \\
\hline 7 & GB319 & - & 0.85 & - & - & - & - & - \\
\hline 7 & GB372 & - & 0.87 & 0.88 & - & - & - & - \\
\hline 7 & GB482 & - & - & 0.84 & - & - & - & - \\
\hline 7 & KG817 & - & - & 0.73 & - & - & - & - \\
\hline 7 & MS0046.01 & - & 0.60 & 0.71 & - & - & - & - \\
\hline 7 & MS0046.02 & - & - & 0.81 & 0.52 & 0.68 & 0.31 & 0.68 \\
\hline 7 & MS0061.02 & - & - & - & 0.47 & 0.68 & 0.22 & - \\
\hline 7 & MS0170.02 & - & 0.87 & 1.00 & - & - & - & 0.75 \\
\hline
\end{tabular}


compared with those of the parents to identify possible off-type seedlings. SSR markers segregating in the progenies were scored as "h," "a," or "u" for presence, absence, or unknown, respectively for each allele. Similarly, disease response was scored as " $h$ " for resistant or "a" for susceptible. Mapping was performed using JoinMap 5 (Kyazma), with "BC1" as the population type, Kosambi as the mapping function, and a LOD threshold of $\geq 6$ for grouping. After the initial mapping, scores for markers and disease response in the spreadsheet were placed in columns in order by position in the reference mapping population and inspected for conflicts. The genome coordinates of the markers were also consulted. If the scores for disease response and presence of the flanking markers were in conflict, the disease response was rescored as " $u$ " for unknown and a new map was drawn. Initially, separate maps were constructed for progenies 13030 and 13031 segregating for resistance from Sochi selection OSU 1166.123, and then a single map was constructed for this parent from the combined data.

\section{Results}

Alignment of the sequences of SSR and ddRAD-Seq markers with the genome sequence of 'Jefferson' (V2) identified 17 PacBio contigs for development of additional SSR markers. A total of 5455 SSR loci with repeat motifs of 2 to $6 \mathrm{bp}$ were found in these PacBio contigs. The number of SSRs by repeat length are 3008 di-nucleotide, 723 tri-nucleotide, 737 tetra-nucleotide, 223 penta-nucleotide, and 764 hexa-nucleotide repeats (Table 4). AT-rich repeats were the most abundant, accounting for 3273 $(60 \%)$ of the total. Di-nucleotide repeats were the most common motifs, and only di-nucleotide repeats were pursued. After removal of the 1870 sequences with only AT repeats, 1138 di-nucleotide repeats remained. Visual screening of aligned sequences with Tablet software identified 373 SSRs as clearly polymorphic, showing variation in the number of repeats but conserved flanking regions and $\geq 3$ alleles. Alignment of the 373 sequences with the ClustalW tool indicated that 22 were duplicates. A BLAST search against previously developed SSRs in the $\mathrm{Na}-$ tional Center for Biotechnology Information (NCBI, Bethesda, MD) GenBank indicated that 341 of the 351 nonredundant sequences had not previously been used for marker development. Nonfluorescent primers were designed from the flanking regions for 96 of them using Primer 3 software and used to amplify DNA of 24 hazelnut accessions. Of these, 45 loci were clearly polymorphic on agarose gels and had one or two bands of the expected size. The other 49 primer pairs were not investigated further because they appeared to be monomorphic on agarose gels or failed to amplify any products. Then, forward primers with a fluorescent tag were ordered, 26 with FAM and 19 with HEX (Supplemental Table 2). In the set of 45 new SSRs, the most common motifs are AG (26.6\%) and CT (26.6\%). The new SSRs were characterized (Table 5) using 50 hazelnut accessions. A total of 458 alleles were amplified, with an average of 10.18 per marker (range 2-23). Expected heterozygosity $\left(\mathrm{H}_{\mathrm{e}}\right)$ averaged 0.72 and ranged from 0.374 to 0.927 . Observed heterozygosity $\left(\mathrm{H}_{\mathrm{o}}\right)$ averaged 0.64 and ranged from 0.16 to 0.94 . PIC values averaged 0.68 and ranged from 0.345 to 0.912 . The most informative markers were MS0046.01, MS0026.08, and MS0113.03, with PIC values of $0.91,0.89$, and 0.86 , respectively. The least informative markers were MS0074.08, MS0076.08, MS0074.6, and MS0061.05, with PIC values $<0.40$. These four markers
Table 4. Number of simple sequence repeats by motif length detected in 17 contigs of the genome sequence (V2) of 'Jefferson' hazelnut. For each motif length, the number of sequences that only contain bases A \& T and those with other motifs.

\begin{tabular}{lrcc}
\hline & \multicolumn{3}{c}{ Simple sequence repeats (no.) } \\
\cline { 2 - 4 } Motif length & Total & Only A \& T & Other motifs \\
\hline Di-nucleotide & 3008 & 1870 & 1138 \\
Tri-nucleotide & 723 & 512 & 211 \\
Tetra-nucleotide & 737 & 522 & 215 \\
Penta-nucleotide & 223 & 109 & 114 \\
Hexa-nucleotide & 764 & 260 & 504 \\
Total & 5455 & 3273 & 2182 \\
\hline
\end{tabular}

also had low observed heterozygosity $\left(\mathrm{H}_{\mathrm{o}}<0.5\right)$ and fewer than six alleles. The average frequency of null alleles in the $45 \mathrm{SSRs}$ was 0.068 , and the range was from -0.09 to 0.47 . The frequency of null alleles was $>0.20$ for eight markers (Table 5).

Primer pairs for the 45 new SSRs were used to amplify the 138 seedlings and the parents of the reference mapping population. Of the 42 markers that segregated, 25 showed a 1:1 ratio, 13 showed a 1:1:1:1 ratio, and 4 showed a 1:2:1 ratio (Table 6). Segregation distortion was observed at marker MS0107.05 on LG2, preventing JoinMap from placing it on the map; but two other markers from the same contig mapped to LG2. The three SSRs that failed to segregate in the mapping population were assigned to a linkage group based on other SSRs developed from the same V2 contig (MS0026.07 and MS0107.04 to LG2, and MS0046.05 to LG7), which was consistent with their coordinates in the V3 genome. Of the 45 markers, 24 were assigned to LG2 and 15 to LG 7, while SSRs developed from contigs 74, 294, and 535 were placed on LGs 10, 9, and 10 respectively (Table 6). Maps are presented for LG2 (Fig. 1) and LG7 (Fig. 2). Although all segregating markers were assigned to a LG, the step-by-step procedure for map construction removed a few markers because they fell out at LOD $<6$, and other markers were removed from the maps of one parent because of poor fit. The positions of the same markers in the maps of the female and male parent were in general agreement but showed slight shifts. A notable exception were the markers with prefix MS0113 that were not placed on LG2F because of very large gaps from the other markers, and in spite of their good fit on the map of LG2M.

Disease SCORES, SEGREgATION RATIOS, AND CORRELATION WITH SSR MARKERS. Segregation ratios for disease response (Table 7) fit the expected 1:1 ratio in four progenies $(10015,11024$, 12030 , and 14035), but ratios showed a deficiency of susceptible seedlings in three progenies (13030, 13031, and 14031). In both field-inoculated progenies of OSU 1166.123 progenies (13030 and 13031), around $63 \%$ of the seedlings were scored as resistant, and segregation in neither progeny fit a $1: 1$ or $3: 1$ ratio. Homogeneity chi-square tests showed that the data from these two progenies could be pooled $\left(\chi^{2}=0.002, P=0.97\right)$. In progeny 14035, segregating for resistance from H3R12P62, about $63 \%$ of the seedlings were resistant and did not fit either a $1: 1$ or $3: 1$ segregation ratio. Disease scores in seedlings of OSU 1187.101 were correlated with scores for markers on LG2; while for Moscow \#2, Moscow \#27, OSU 1166.123, and H3R12P62 disease scores were correlated with scores for markers on LG7 (Table 3). Progeny 14031, segregating for resistance from Rutgers University selection $\mathrm{H} 3 \mathrm{R} 07 \mathrm{P} 11$, has $\approx 63 \%$ resistant seedlings. The 
Table 5. Characteristics of 45 new simple sequence repeat markers developed from the genome sequence (V2) of 'Jefferson' hazelnut. The sequences are available from the National Center for Biotechnology Information under the listed GenBank numbers.

\begin{tabular}{|c|c|c|c|c|c|c|c|c|}
\hline Marker & GenBank no. & Repeat motif & Linkage group & Alleles (no.) & $\begin{array}{c}\text { Expected } \\
\text { heterozygosity }\end{array}$ & $\begin{array}{c}\text { Observed } \\
\text { heterozygosity }\end{array}$ & PIC & $\begin{array}{c}\text { Frequency of } \\
\text { null alleles }\end{array}$ \\
\hline MS0026.03 & MT181628 & $(\mathrm{CT}) 16$ & 2 & 15 & 0.86 & 0.92 & 0.83 & -0.04 \\
\hline MS0026.04 & MT181629 & (TC) 18 & 2 & 11 & 0.78 & 0.42 & 0.75 & 0.30 \\
\hline MS0026.07 & MT181630 & (AC) 11 & 2 & 10 & 0.77 & 0.71 & 0.73 & 0.04 \\
\hline MS0026.08 & MT181631 & (GA) 17 & 2 & 22 & 0.91 & 0.92 & 0.89 & -0.01 \\
\hline MS0026.10 & MT181632 & $(A G) 10$ & 2 & 6 & 0.47 & 0.42 & 0.43 & 0.07 \\
\hline MS0026.11 & MT181633 & (CT) 15 & 2 & 10 & 0.77 & 0.40 & 0.73 & 0.32 \\
\hline MS0026.13 & MT181634 & (TC) 17 & 2 & 10 & 0.80 & 0.33 & 0.77 & 0.42 \\
\hline MS0026.14 & MT181635 & $(\mathrm{AG}) 10$ & 2 & 13 & 0.88 & 0.82 & 0.86 & 0.03 \\
\hline MS0107.02 & MT181651 & (TC) 18 & 2 & 9 & 0.82 & 0.76 & 0.78 & 0.04 \\
\hline MS0107.03 & MT181652 & (CT) 16 & 2 & 12 & 0.82 & 0.86 & 0.78 & -0.03 \\
\hline MS0107.04 & MT181653 & $(\mathrm{CT}) 8$ & 2 & 5 & 0.42 & 0.16 & 0.39 & 0.47 \\
\hline MS0107.05 & MT181654 & $(\mathrm{AG}) 11$ & 2 & 10 & 0.84 & 0.90 & 0.81 & -0.04 \\
\hline MS0113.01 & MT181655 & (TC) 19 & 2 & 9 & 0.79 & 0.80 & 0.75 & -0.02 \\
\hline MS0113.02 & MT181656 & (TC) 11 & 2 & 13 & 0.82 & 0.31 & 0.79 & 0.46 \\
\hline MS0113.03 & MT181657 & $(A G) 16$ & 2 & 20 & 0.88 & 0.90 & 0.86 & -0.02 \\
\hline MS0113.04 & MT181658 & $(\mathrm{AG}) 16$ & 2 & 12 & 0.79 & 0.92 & 0.75 & -0.09 \\
\hline MS0113.06 & MT181659 & (GA)18 & 2 & 10 & 0.76 & 0.87 & 0.72 & -0.08 \\
\hline MS0121.02 & MT181661 & (TC) 16 & 2 & 11 & 0.81 & 0.80 & 0.77 & 0.00 \\
\hline MS0121.04 & MW396735 & (GA)16 & 2 & 15 & 0.81 & 0.71 & 0.78 & 0.06 \\
\hline MS0140.02 & MT181663 & (CT) 14 & 2 & 7 & 0.67 & 0.74 & 0.60 & -0.08 \\
\hline MS0140.04 & MT181664 & (CT) 20 & 2 & 3 & 0.55 & 0.51 & 0.47 & 0.01 \\
\hline MS0140.05 & MT181665 & $(A G) 13$ & 2 & 5 & 0.60 & 0.67 & 0.53 & -0.07 \\
\hline MS0229.02 & MT181667 & (CT)12 & 2 & 16 & 0.81 & 0.70 & 0.79 & 0.07 \\
\hline MS0284.01 & MT181670 & $(\mathrm{AG}) 11$ & 2 & 8 & 0.73 & 0.56 & 0.68 & 0.13 \\
\hline MS0046.01 & MT181636 & (TC) 22 & 7 & 23 & 0.93 & 0.94 & 0.91 & -0.01 \\
\hline MS0046.02 & MT181637 & (CT) 18 & 7 & 11 & 0.80 & 0.71 & 0.76 & 0.06 \\
\hline MS0046.05 & MT181638 & (TC)9 & 7 & 10 & 0.57 & 0.45 & 0.53 & 0.12 \\
\hline MS0046.07 & MT181639 & (GA)13 & 7 & 9 & 0.63 & 0.60 & 0.61 & -0.01 \\
\hline MS0061.02 & MT181640 & (AC) 10 & 7 & 8 & 0.45 & 0.28 & 0.43 & 0.22 \\
\hline MS0061.03 & MT181641 & (CT) 12 & 7 & 9 & 0.70 & 0.62 & 0.65 & 0.08 \\
\hline MS0061.04 & MT181642 & $(\mathrm{GA}) 12$ & 7 & 4 & 0.68 & 0.66 & 0.62 & 0.02 \\
\hline MS0061.05 & MT181643 & (AG) 15 & 7 & 4 & 0.46 & 0.49 & 0.37 & -0.04 \\
\hline MS0076.03 & MT181648 & $(\mathrm{GA}) 12$ & 7 & 2 & 0.50 & 0.42 & 0.37 & 0.09 \\
\hline MS0076.04 & MT181649 & (CT)17 & 7 & 10 & 0.75 & 0.60 & 0.71 & 0.11 \\
\hline MS0076.08 & MT181650 & $(\mathrm{AG}) 9$ & 7 & 2 & 0.50 & 0.32 & 0.37 & 0.21 \\
\hline MS0126.04 & MT181662 & (TC) 16 & 7 & 21 & 0.87 & 0.80 & 0.85 & 0.04 \\
\hline MS0170.02 & MT181666 & $(\mathrm{AG}) 12$ & 7 & 12 & 0.72 & 0.72 & 0.68 & 0.00 \\
\hline MS0230.01 & MT181668 & (CT)15 & 7 & 12 & 0.86 & 0.88 & 0.83 & -0.02 \\
\hline MS0230.03 & MT181669 & (GA)16 & 7 & 15 & 0.83 & 0.80 & 0.80 & 0.02 \\
\hline MS0294.03 & MT181671 & $(\mathrm{AC}) 8$ & 9 & 11 & 0.86 & 0.76 & 0.83 & 0.06 \\
\hline MS0074.02 & MT181644 & (TC) 15 & 10 & 12 & 0.78 & 0.81 & 0.74 & -0.03 \\
\hline MS0074.03 & MT181645 & $(\mathrm{AG}) 15$ & 10 & 10 & 0.80 & 0.82 & 0.76 & -0.02 \\
\hline MS0074.06 & MT181646 & (CT) 10 & 10 & 2 & 0.50 & 0.28 & 0.37 & 0.27 \\
\hline MS0074.08 & MT181647 & $(\mathrm{AG}) 11$ & 10 & 5 & 0.37 & 0.40 & 0.35 & -0.07 \\
\hline MS0535.01 & MT181672 & (TC)12 & 10 & 4 & 0.73 & 0.69 & 0.68 & 0.02 \\
\hline Mean & & & & 10.2 & 0.72 & 0.65 & 0.68 & 0.07 \\
\hline
\end{tabular}

$\overline{\mathrm{PIC}}=$ polymorphism information content.

disease response ratio did not fit either a 1:1 or 3:1 segregation ratio [1:1 ratio: $\chi^{2}=4.26, P=0.038$; and 3:1 ratio: $\chi^{2}=4.35, P=$ 0.037 (Table 7)]. Disease response in this progeny was not correlated with marker scores for SSRs on LG6, LG2, or LG7 $(r<5)$, indicating that resistance may be on one of the other eight chromosomes.

Mapping of EFB REsistance. After the linkage group had been identified, the newly developed SSR markers and several easy-to-score SSR markers previously assigned to that LG and located within $20 \mathrm{cM}$ of a previously mapped resistance locus were used to amplify the parents and seedlings. Maps were constructed for six of the seven progenies, all except for H3R07P11. All seedlings in each progeny were genotyped with the selected SSR markers. In progeny 13031 (OSU $1166.123 \times$ OSU 1236.134), comparison of SSR marker scores in the seedlings and parents indicated that 17 of the 94 seedlings were not from 
Table 6. Segregation at 42 new simple sequence repeat marker loci in the hazelnut (Corylus avellana) reference mapping population (OSU 252.146 x OSU 414.062) and linkage group assignment.

\begin{tabular}{|c|c|c|c|c|c|c|c|}
\hline \multirow[b]{2}{*}{ Marker } & \multirow[b]{2}{*}{ Parent alleles } & \multicolumn{2}{|c|}{ Segregation ratio } & \multicolumn{3}{|c|}{$\chi^{2}$} & \multirow[b]{2}{*}{ Allele and linkage group } \\
\hline & & Expected & Observed & df & Value & $P$ & \\
\hline$\overline{M S 0026.03}$ & $294 / 294 \times 281 / 296$ & $1: 1$ & $65: 62$ & 1 & 0.071 & 0.790 & 296 on $2 \mathrm{M}$ \\
\hline MS0026.04 & $205 / 205 \times 195 / 205$ & $1: 1$ & $69: 76$ & 1 & 0.338 & 0.561 & $195 \mathrm{~d}$ on $2 \mathrm{M}$ (poor fit) \\
\hline MS0026.08 & $277 / 287 \times 271 / 283$ & $1: 1: 1: 1$ & $26: 38: 41: 28$ & 3 & 4.895 & 0.180 & 277 on $2 \mathrm{~F}, 271$ on $2 \mathrm{M}$ \\
\hline MS0026.10 & $251 / 255 \times 251 / 257$ & $1: 1: 1: 1$ & $38: 29: 34: 37$ & 3 & 1.420 & 0.701 & $255 \mathrm{~d}$ on $2 \mathrm{~F}, 257$ on $2 \mathrm{M}$ \\
\hline MS0026.11 & $281 / 293 \times 295 /$ null & $1: 1: 1: 1$ & $31: 36: 41: 29$ & 3 & 2.533 & 0.469 & 281 on $2 \mathrm{~F}, 295$ on $2 \mathrm{M}$ \\
\hline MS0026.13 & $242 / 260 \times 260 / 260$ & $1: 1$ & $72: 66$ & 1 & 0.261 & 0.609 & 242 on $2 F$ \\
\hline MS0026.14 & $260 / 262 \times 270 / 270$ & $1: 1$ & $67: 71$ & 1 & 0.116 & 0.733 & 260 on $2 \mathrm{~F}$ \\
\hline MS0107.02 & $162 / 162 \times 166 / 170$ & $1: 1$ & $72: 64$ & 1 & 0.471 & 0.493 & 170 on $2 \mathrm{M}$ \\
\hline MS0107.03 & $216 / 216 \times 203 / 209$ & $1: 1$ & $72: 64$ & 1 & 0.471 & 0.493 & 209 on $2 \mathrm{M}$ \\
\hline MS0107.05 & $208 / 208 \times 210 / 212$ & $1: 1$ & $90: 48$ & 1 & 12.783 & 0.000 & unmapped (distorted) \\
\hline MS0113.01 & $277 / 277 \times 273 / 288$ & $1: 1$ & $63: 70$ & 1 & 0.368 & 0.544 & 288 on $2 \mathrm{M}$ \\
\hline MS0113.02 & $264 / 264 \times 264 / 272$ & $1: 1$ & $59: 69$ & 1 & 0.781 & 0.377 & 272 on $2 \mathrm{M}$ \\
\hline MS0113.03 & $193 / 213 \times 210 / 210$ & $1: 1$ & $64: 66$ & 1 & 0.031 & 0.861 & 193 on $2 \mathrm{~F}$ \\
\hline MS0113.04 & $199 / 211 \times 201 / 203$ & $1: 1: 1: 1$ & $34: 33: 41: 33$ & 3 & 1.270 & 0.736 & 212 on $2 F$ \\
\hline MS0113.06 & $313 / 315 \times 313 / 315$ & $1: 2: 1$ & $30: 76: 23$ & 2 & 4.860 & 0.088 & $312 \mathrm{hk}$ on $2 \mathrm{~F}$ (poor fit) \\
\hline MS0121.02 & $259 / 262 \times 269 / 272$ & $1: 1: 1: 1$ & $39: 36: 27: 33$ & 3 & 2.333 & 0.506 & 262 on $2 \mathrm{~F}, 272$ on $2 \mathrm{M}$ \\
\hline MS0121.04 & $250 / 255 \times 257 / 257$ & $1: 1$ & $61: 70$ & 1 & 0.618 & 0.432 & 250 on $2 F$ \\
\hline MS0140.02 & $259 / 259 \times 259 / 261$ & $1: 1$ & $72: 68$ & 1 & 0.114 & 0.735 & 261 on $2 \mathrm{M}$ \\
\hline MS0140.04 & $132 / 132 \times 130 / 136$ & $1: 1$ & $72: 66$ & 1 & 0.261 & 0.610 & 136 on $2 \mathrm{M}$ \\
\hline MS0140.05 & $280 / 280 \times 278 / 284$ & $1: 1$ & $71: 66$ & 1 & 0.182 & 0.669 & 284 on $2 \mathrm{M}$ \\
\hline MS0229.02 & $287 / 287 \times 275 /$ null & $1: 1$ & $63: 60$ & 1 & 0.073 & 0.787 & null on $2 \mathrm{M}$ \\
\hline MS0230.01 & $195 / 195 \times 208 / 210$ & $1: 1$ & $65: 72$ & 1 & 0.358 & 0.550 & 208 on $2 \mathrm{M}$ \\
\hline MS0230.03 & $266 / 266 \times 260 / 268$ & $1: 1$ & $70: 61$ & 1 & 0.618 & 0.432 & 268 on $2 \mathrm{M}$ \\
\hline MS0284.01 & $259 / 259 \times 253 / 259$ & $1: 1$ & $70: 69$ & 1 & 0.007 & 0.932 & $253 \mathrm{~d}$ on $2 \mathrm{M}$ \\
\hline MS0046.01 & $278 / 291 \times 270 / 270$ & $1: 1$ & $57: 66$ & 1 & 0.659 & 0.417 & 291 on $7 F$ \\
\hline MS0046.02 & $171 / 187 \times 179 / 183$ & $1: 1: 1: 1$ & $32: 34: 33: 39$ & 3 & 0.841 & 0.840 & 187 on $7 \mathrm{~F}, 183$ on $7 \mathrm{M}$ \\
\hline MS0046.07 & $139 / 139 \times 139 / 149$ & $1: 1$ & $68: 77$ & 1 & 0.694 & 0.405 & 149 on $7 \mathrm{M}$ \\
\hline MS0061.02 & $176 / 182 \times 182 / 187$ & $1: 1: 1: 1$ & $32: 44: 34: 35$ & 3 & 2.338 & 0.505 & 176 on $7 \mathrm{~F}, 187$ on $7 \mathrm{M}$ \\
\hline MS0061.03 & $85 / 89 \times 85 / 91$ & $1: 1: 1: 1$ & $34: 36: 32: 44$ & 3 & 2.274 & 0.518 & 89 on $7 \mathrm{~F}, 91$ on $7 \mathrm{M}$ \\
\hline MS0061.04 & $178 / 180 \times 178 / 180$ & $1: 2: 1$ & $34: 69: 42$ & 2 & 1.221 & 0.543 & $180 \mathrm{hk}$ on $7 \mathrm{~F}$ with MS0061.02-176F \\
\hline MS0061.05 & $259 / 259 \times 259 / 261$ & $1: 1$ & $65: 79$ & 1 & 1.361 & 0.243 & 261 on $7 \mathrm{M}$ \\
\hline MS0076.03 & $169 / 171 \times 169 / 171$ & $1: 2: 1$ & $32: 71: 41$ & 2 & 1.153 & 0.562 & 171hk on $7 \mathrm{~F}$ with GB467 \\
\hline MS0076.04 & $284 / 291 \times 284 / 291$ & $1: 2: 1$ & $42: 72: 32$ & 2 & 1.397 & 0.497 & $284 \mathrm{hk}$ on $7 \mathrm{~F}, 180 \mathrm{hk}$ on $7 \mathrm{M}$ \\
\hline MS0076.08 & $172 / 172 \times 168 / 172$ & $1: 1$ & $76: 68$ & 1 & 0.444 & 0.505 & 168 on $7 \mathrm{M}$ \\
\hline MS0126.04 & $278 / 291 \times 289 /$ null & $1: 1: 1: 1$ & $32: 31: 40: 32$ & 3 & 1.563 & 0.668 & 291 on $7 F, 289$ on $7 \mathrm{M}$ \\
\hline MS0170.02 & $139 / 141 \times 139 / 148$ & $1: 1: 1: 1$ & $35: 36: 34: 41$ & 3 & 0.795 & 0.851 & 141 on $7 \mathrm{~F}, 1847 \mathrm{M}$ \\
\hline MS0074.02 & $255 / 255 \times 255 / 268$ & $1: 1$ & $59: 80$ & 1 & 3.173 & 0.075 & $268 \mathrm{~d}$ on $10 \mathrm{M}$ near $\mathrm{KG} 826$ \\
\hline MS0074.03 & $189 / 201 \times 201 / 209$ & $1: 1: 1: 1$ & $37: 33: 27: 48$ & 3 & 6.476 & 0.091 & $\begin{array}{l}\text { 189d on } 10 \mathrm{~F} \text { near GB949, 209d on } \\
10 \mathrm{M} \text { near KG826 }\end{array}$ \\
\hline MS0074.06 & $205 / 205 \times 203 / 205$ & $1: 1$ & $81: 63$ & 1 & 2.250 & 0.134 & $203 \mathrm{~d}$ on $10 \mathrm{M}$ near GB724 \\
\hline MS0074.08 & $154 / 156 \times 154 / 154$ & $1: 1$ & $70: 74$ & 1 & 0.111 & 0.739 & 156 on $10 \mathrm{~F}$ near $\mathrm{AC} 01-840 \mathrm{~d}$ \\
\hline MS0294.03 & $203 / 204 \times 199 / 203$ & $1: 1: 1: 1$ & $35: 33: 34: 42$ & 3 & 1.389 & 0.708 & $\begin{array}{l}204 \text { on } 9 \mathrm{~F} \text { near } 636-350,199 \text { on } \\
9 \mathrm{M} \text { near GB725 }\end{array}$ \\
\hline MS0535.01 & $244 / 267 \times 240 / 243$ & $1: 1: 1: 1$ & $37: 31: 41: 29$ & 3 & 2.638 & 0.451 & $\begin{array}{l}267 \text { on } 10 \mathrm{~F} \text { near } \mathrm{AC} 01-840 \mathrm{~d}, 243 \text { on } \\
10 \mathrm{M} \text { near } 363-1600\end{array}$ \\
\hline
\end{tabular}

those parents. Hence, they were removed, and a new map constructed for the progeny. After the initial mapping, comparison of disease scores revealed a few conflicts with the scores of the flanking SSR markers. Some seedlings lacked cankers, but the SSR marker data indicated susceptibility. We considered them to have escaped infection, changed the disease phenotype from "resistant" to "unknown," and then redrew the map. A few seedlings were scored as susceptible while marker data indicated resistance. This type of conflict may have resulted from phenotyping errors or recombination between the marker and disease resistance loci. An additional possibility is that resistant seedlings occasionally develop small cankers (Lunde et al., 2006); and in fact, trees of 'Jefferson' and 'McDonald' with 'Gasaway' resistance in orchards under high disease pressure trees occasionally develop cankers (Pscheidt and Ocamb, 2020). In these situations, the disease score was changed to "unknown," and the map redrawn. A. anomala has a 2-year life cycle with a 15-month latent period; and although the April assessment of disease response was only 13 months after the inoculation, the August assessment was 17 months after inoculation. The map 

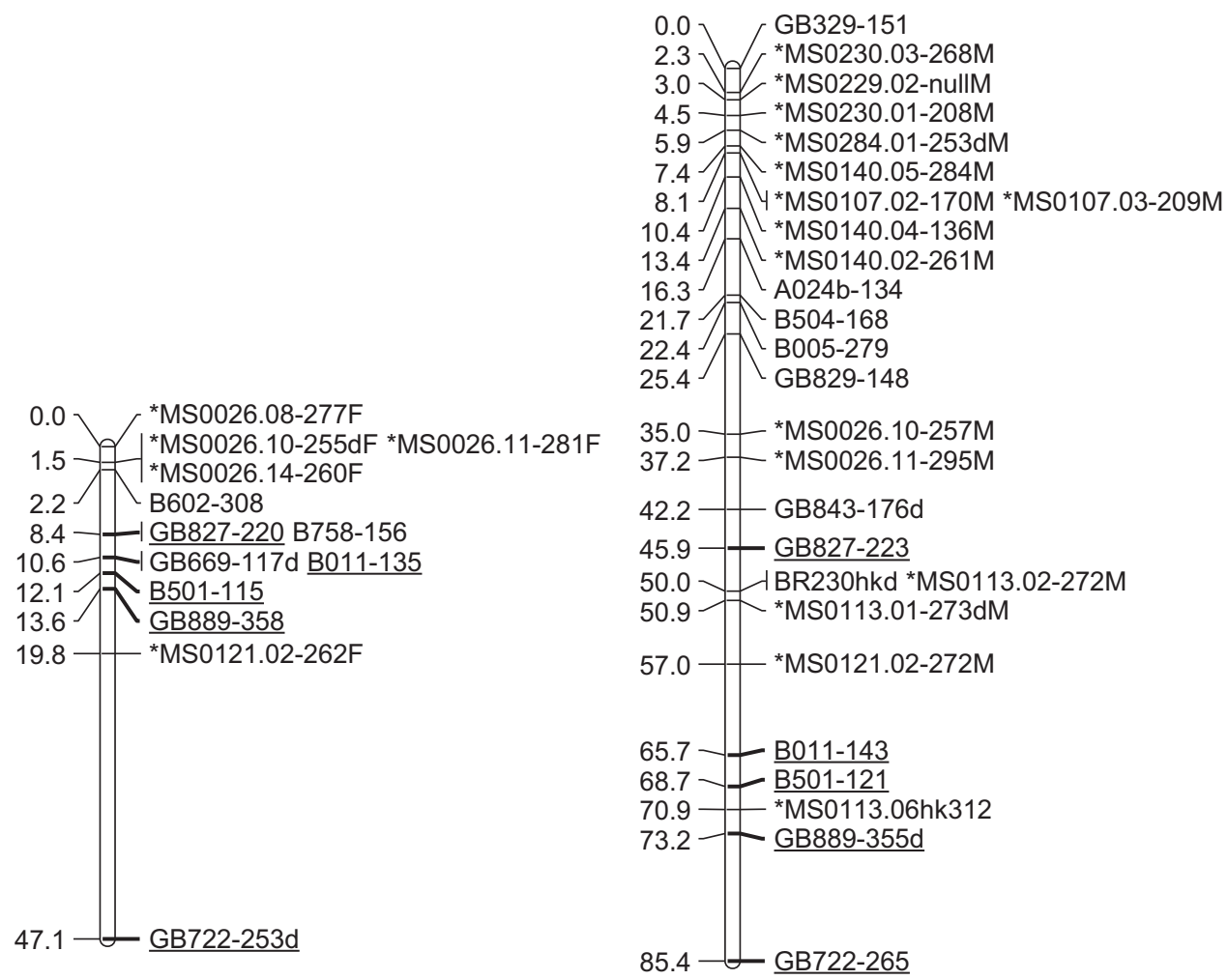

Fig. 1. Maps of hazelnut linkage group 2 (LG2) in female parent OSU 252.146 and male parent OSU 414.062 in the reference mapping populations constructed using simple sequence repeat markers. New markers are indicated with an asterisk $\left({ }^{*}\right)$, and markers common to the maps of the parents are underlined.

for progeny 10015 placed resistance from OSU 1187.101 at the proximal end of LG2 closest to marker B504 (Fig. 3). The map for progeny 11024 (Fig. 4) placed resistance from Moscow \#2 on LG7 between markers B020 and MS0046.01 on one side, and B751 on the other side. The map for progeny 12030 (Fig. 4) placed resistance from Moscow \#27 on LG7 between markers B020 and GB482. The map for progenies 13030 and 13031 (Fig. 4) segregating for resistance from OSU 1166.123 placed resistance on LG7 between markers B509 and B753. The map for progeny 14035 (Fig. 4) placed resistance from Rutgers University selection H3R12P62 on LG7, co-segregating with markers B020, B753, and MS0046.07.

\section{Discussion}

In silico approaches for developing polymorphic SSR markers have gained in popularity because of their efficiency and low cost compared with traditional methods (Hoffman and Nichols, 2011; Vukosavljev et al., 2015; Zhang et al., 2013). In silico SSR detection has been reported in different crop species including tomato (Solanum lycopersicum), potato (Solanum tuberosum), and rice (Oryza sativa) (Tang et al., 2008), Typha minima (Csencsics et al., 2010), peanut [Arachis hypogaea
(Shirasawa et al., 2012)], and pistachio [Pistacia vera (Khodaeiaminjan et al., 2018)]. In hazelnut, Boccacci et al. (2015), Colburn et al. (2017), and Bhattarai and Mehlenbacher (2017, 2018) used in silico mining to develop SSRs from expressed sequence tags (ESTs), transcriptome, and genomic sequences, respectively. In this study, genomic SSRs were developed in two regions where EFB resistance had previously been mapped. In 17 PacBio sequence contigs of 'Jefferson', a total of 5455 microsatellites were detected, and primers designed for a subset of dinucleotide repeats. Additional ones could be pursued in the future. Many of those considered "not clearly polymorphic" on agarose gels would likely show polymorphism if scored by capillary electrophoresis. For the markers that were difficult to score, new primers could be designed or pig-tailing pursued (Brownstein et al., 1996). Only di-nucleotide repeats were pursued because they tend to have higher polymorphism and because SSRs with longer repeat motifs had been developed by Bhattarai and Mehlenbacher $(2017,2018)$ and Colburn et al. (2017). Based on the results of Gürcan and Mehlenbacher (2010b) and Boccacci et al. (2015), we expect many of these SSRs to be useful in other species of Corylus and the related genera Betula and Alnus.

Of the 45 new SSR marker loci, segregation in the mapping population was observed at 42 of them. On LG2 (Scaffold 1), 24 


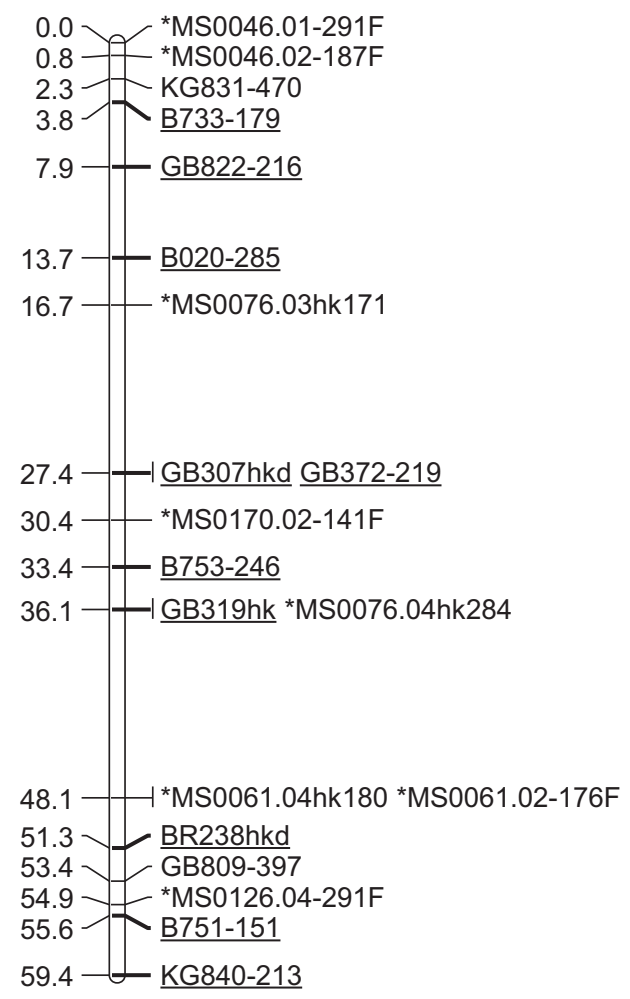

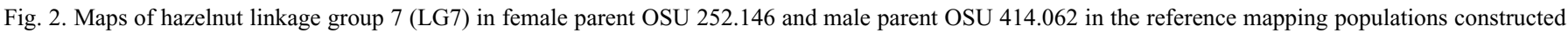
using simple sequence repeat markers. New markers are indicated with an asterisk $(*)$, and markers common to the maps of the parents are underlined.

SSRs were developed from 7 contigs, while 15 SSRs developed from 6 contigs were placed on LG7 (Scaffold 7). The coordinates of the new SSR markers were identified in the V2 and V3 'Jefferson' genomes (Supplemental Table 3). The markers on LG2 are on scaffold 1 in positions from 47,025 bp to 17,687,764 bp. The markers on LG7 are on scaffold 7 in positions from $1,191,371$ to $17,584,843$. On the linkage maps, as in the V3 genome, the new SSR markers cover large distances. Of the newly developed SSR loci, the most useful are easily scored markers with high PIC values and low frequency of null alleles. On LG2 (Fig. 1), MS0026.08, MS0026.10, MS0026.11, and MS0026.14 are four that meet these criteria and are in the region where EFB resistance from Georgian selection OSU 759.010 (Sathuvalli et al., 2011b) and H3R07P25 from Holmskij, Russia (Honig et al., 2019) was mapped. On LG7 (Fig. 2), MS0046.02, MS0046.07, MS0061.02, MS0061.03, MS0061.05, MS0076.08, and MS0170.02 meet these criteria and are in the region where

Table 7. Segregation for eastern filbert blight resistance in seven hazelnut (Corylus avellana) progenies.

\begin{tabular}{|c|c|c|c|c|c|c|c|c|}
\hline & & \multirow[b]{2}{*}{ Origin of resistance } & \multirow{2}{*}{$\begin{array}{l}\text { Inoculation } \\
\text { method }\end{array}$} & \multicolumn{2}{|c|}{ Plants (no.) } & \multirow{2}{*}{$\begin{array}{l}\text { Expected } \\
\text { ratio }\end{array}$} & \multicolumn{2}{|c|}{ Chi-squared $^{\mathrm{z}}$} \\
\hline Progeny & Parents $($ female $\times$ male $)$ & & & Resistant & Susceptible & & Value & $P$ \\
\hline 10015 & OSU $1187.101 \times$ OSU 1155.049 & Holmskij, Russia (RUS-10) & Structure & 67 & 52 & $1: 1$ & 1.891 & 0.169 \\
\hline 12030 & OSU $1269.020 \times$ Moscow \#27 & Moscow, Russia & Structure & 39 & 31 & $1: 1$ & 0.914 & 0.339 \\
\hline 13030 & OSU $1166.123 \times$ OSU 1235.078 & Sochi, Russia & Field & 50 & 29 & $1: 1$ & 5.582 & 0.018 \\
\hline 13031 & OSU $1166.123 \times$ OSU 1236.134 & Sochi, Russia & Field & 49 & 28 & $1: 1$ & 5.727 & 0.017 \\
\hline
\end{tabular}

\footnotetext{
${ }^{\mathrm{z}}$ One degree of freedom for all Chi-squared tests.
} 


\section{LG2-Holmskij}

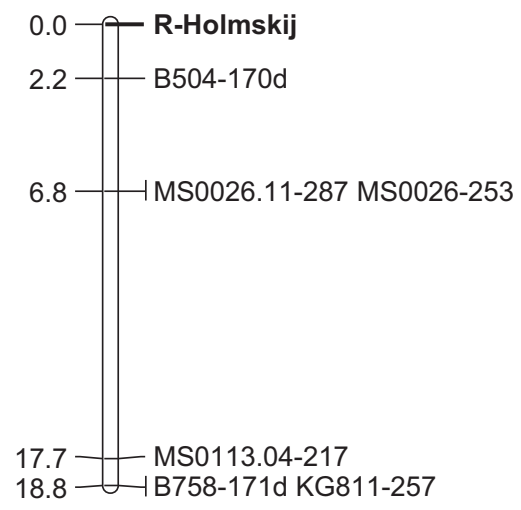

Fig. 3. Map of linkage group 2 (LG2) in hazelnut progeny 10015 segregating for OSU 1187.101 resistance from Holmskij, Russia.

EFB resistance from 'Ratoli' was mapped (Sathuvalli et al., 2011a). These new SSR markers will be useful in future studies of EFB resistance, cultivar fingerprinting, diversity studies, and marker-assisted selection, including the pyramiding of resistance genes. Future mapping efforts in

\section{LG7-Moscow\#2}

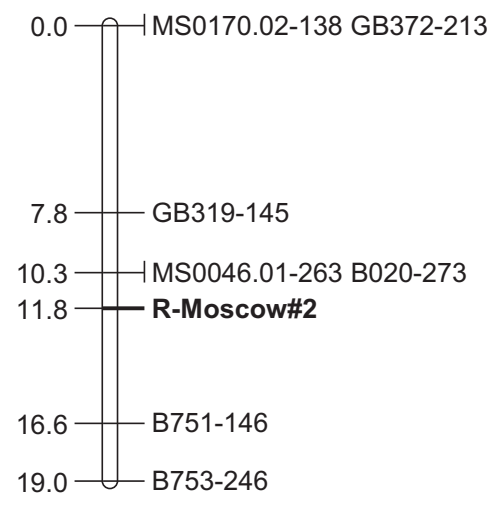

LG2 and LG7, and the merger of the two linkage groups in the

\section{LG7-Moscow\#27}
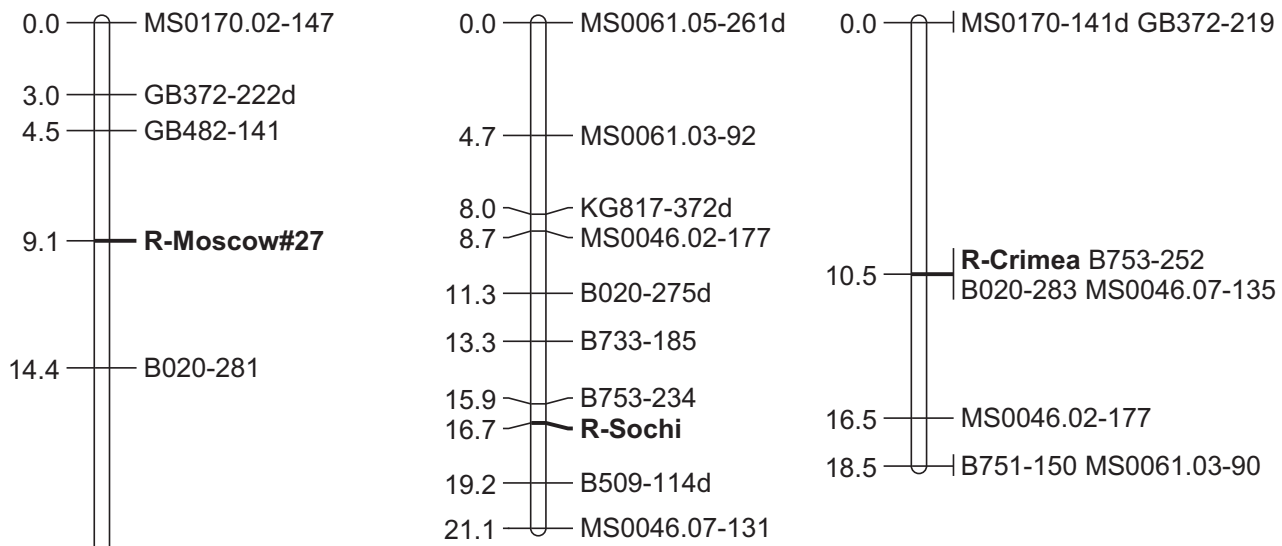
map of the male parent (Mehlenbacher and Bhattarai, 2018; Mehlenbacher et al., 2006). This was attributed to a reciprocal translocation involving LG2 and LG7 (Komaei Koma, 2020; Salesses, 1973; Salesses and Bonnet, 1988). Komaei Koma (2020) used

populations without a translocation involving LG2 and LG7 would clarify the marker positions.

Resistance was expected to be controlled by a single locus and that each resistant parent was heterozygous. However, deviation from the expected 1:1 segregation ratio (resistance: susceptible) was seen in four progenies in this study. In several previous studies, segregation distortion for EFB response was observed for 'Culpla', 'Crvenje', Russian OSU 495.072 (Colburn et al., 2015), 'Uebov' (Bhattarai et al., 2017a), and 'Zimmerman' (Lunde et al., 2006). In some progenies, there is an excess of resistant seedlings; while in others, there is an excess of susceptible seedlings. Segregation distortion has been documented in various plant species for several traits and is attributed to a diverse array of mechanisms. Previous mapping revealed segregation distortion at loci on

\section{LG7-Sochi LG7-Crimea}

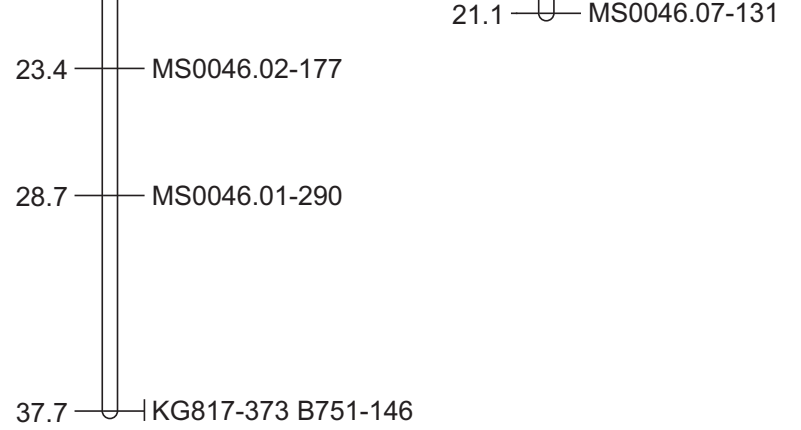

Fig. 4. Maps of linkage group 7 (LG7) in hazelnut progenies segregating for resistance from four sources: Moscow \#2 (progeny 11024 ), Moscow \#27 (progeny 12030), OSU 1166.123 (progenies 13030 and 13031), and Rutgers University selection H3R12P62 (progeny 14035). 
bioinformatic methods to disentangle the "pseudo-linkage" of markers on LG2 and LG7 in the male parent (OSU 414.062). The use of populations segregating for disease response and without a translocation involving LG2 and LG7 would clarify the positions of the resistance loci and markers.

In this study, resistance from Moscow selections \#2 and \#27, OSU 1166.123, and H3R12P62 was placed on LG7; and resistance from OSU 1187.101 was placed on LG2. All five are different from the 'Gasaway' resistance (LG6) that has been extensively used in the OSU hazelnut breeding program. The use of common SSR markers in mapping allows alignment of the various maps of the same LG for different progenies. These new resistance sources and linked SSR markers will allow MAS, including the pyramiding of resistance genes, and facilitate the development of new cultivars with durable EFB resistance.

\section{Literature Cited}

Bassil, N.V., R. Botta, and S.A. Mehlenbacher. 2005a. Additional microsatellite markers of the European hazelnut. Acta Hort. 686:105110, doi: 10.17660/ActaHortic.2005.686.13.

Bassil, N.V., R. Botta, and S.A. Mehlenbacher. 2005b. Microsatellite markers in hazelnut: Isolation, characterization and cross-species amplification. J. Amer. Soc. Hort. Sci. 130:543-549, doi: 10.21273/ JASHS.130.4.543.

Bassil N., P. Boccacci, R. Botta, J. Postman, and S. Mehlenbacher. 2013. Nuclear and chloroplast microsatellite markers to assess genetic diversity and evolution in hazelnut species, hybrids and cultivars. Genet. Resources Crop Evol. 60:543-568, doi: 10.1007/s10722-0129857-z.

Bhattarai, G. and S. Mehlenbacher. 2017. In silico development and characterization of tri-nucleotide simple sequence repeat markers in hazelnut (Corylus avellana L.). PLoS One 12: e0178061, doi: 10.1371/journal.pone.0178061.

Bhattarai, G. and S.A. Mehlenbacher. 2018. Discovery, characterization, and linkage mapping of simple sequence repeat markers in hazelnut. J. Amer. Soc. Hort. Sci. 143:347-362, doi: 10.21273/ Jashs04461-18.

Bhattarai, G., S.A. Mehlenbacher, and D.C. Smith. 2017a. Inheritance and linkage mapping of eastern filbert blight disease resistance in 'Uebov' hazelnut. J. Amer. Soc. Hort. Sci. 142:289-297, doi: 10.21273/jashs04145-17.

Bhattarai, G., S.A. Mehlenbacher, and D.C. Smith. 2017b. Eastern filbert blight disease resistance from Corylus americana 'Rush' and selection 'Yoder \#5' maps to linkage group 7. Tree Genet. Genomes 13(45), doi: 10.1007/s11295-017-1129-9.

Boccacci, P., A. Akkak, N.V. Bassil, S.A. Mehlenbacher, and R. Botta. 2005. Characterization and evaluation of microsatellite loci in european hazelnut (Corylus avellana L.) and their transferability to other Corylus species. Mol. Ecol. Notes 5:934-937, doi: 10.1111/ j.1471-8286.2005.01121.x.

Boccacci, P., C. Beltramo, M.A. Sandoval Prando, A. Lembo, C. Sartor, S.A. Mehlenbacher, R. Botta, and D. Torello Marinoni. 2015. In silico mining, characterization and cross-species transferability of EST-SSR markers for european hazelnut (Corylus avellana L.). Mol. Breed. 35(21), doi: 10.1007/s11032-015-0195-7.

Brownstein, M.J., J.D. Carpten, and J.R. Smith. 1996. Modulation of non-templated nucleotide addition by Taq DNA polymerase: Primer modifications that facilitate genotyping. Biotechniques 20:1004 1010, doi: 10.2144/96206st01.

Cameron, H.R. 1976. Eastern filbert blight established in the Pacific Northwest. Plant Dis. Rptr. 60:737-740.

Capik, J.M. and T.J. Molnar. 2012. Assessment of host (Corylus sp.) resistance to eastern filbert blight in New Jersey. J. Amer. Soc. Hort. Sci. 137:157-172, doi: 10.21273/JASHS.137.3.157.
Capik, J.M., M. Muehlbauer, A. Novy, J.A. Honig, and T.J. Molnar. 2013. Eastern filbert blight-resistant hazelnuts from Russia, Ukraine, and Poland. HortScience 48:466-473, doi: 10.21273/HORTSCI. 48.4.466.

Colburn, B.C., S.A. Mehlenbacher, and V.R. Sathuvalli. 2017. Development and mapping of microsatellite markers from transcriptome sequences of European hazelnut (Corylus avellana L.) and use for germplasm characterization. Mol. Breed. 37(16), doi: 10.1007/ s11032-016-0616-2.

Colburn, B.C., S.A. Mehlenbacher, V.R. Sathuvalli, and D.C. Smith. 2015. Eastern filbert blight resistance in hazelnut accessions 'Culplà', 'Crvenje', and OSU 495.072. J. Amer. Soc. Hort. Sci. 140:191-200, doi: $10.21273 /$ jashs.140.2.191.

Csencsics, D., S. Brodbeck, and R. Holderegger. 2010. Cost-effective, species-specific microsatellite development for the endangered dwarf bulrush (Typha minima) using next-generation sequencing technology. J. Hered. 101:789-793, doi: 10.1093/jhered/esq069.

Davison, A.R. and R.M. Davidson. 1973. Apioporthe and Monochaetia cankers reported in western Washington. Plant Dis. Rep. 57:12601268.

Flor, H.H. 1942. Inheritance of pathogenicity in Melampsora lini. Phytopathology 32:653-669.

Gökirmak, T., S. Mehlenbacher, and N. Bassil. 2009. Characterization of European hazelnut (Corylus avellana) cultivars using SSR markers. Genet. Resources Crop Evol. 56:147-172, doi: 10.1007/ s10722-008-9352-8.

Grattapaglia, D. and R. Sederoff. 1994. Genetic linkage maps of Eucalyptus grandis and Eucalyptus urophylla using a pseudo-testcross: Mapping strategy and RAPD markers. Genetics 137:1121-1137, doi: 10.1093/genetics/137.4.1121.

Gürcan, K. and S.A. Mehlenbacher. 2010a. Development of microsatellite marker loci for European hazelnut (Corylus avellana L.) from ISSR fragments. Mol. Breed. 26:551-559, doi: 10.1007/s11032-0109464-7.

Gürcan, K. and S.A. Mehlenbacher. 2010b. Transferability of microsatellite markers in the Betulaceae. J. Amer. Soc. Hort. Sci. 135: 159-173, doi: 10.21273/JASHS.135.2.159.ü.

Gürcan, K., S.A. Mehlenbacher, R. Botta, and P. Boccacci. 2010. Development, characterization, segregation, and mapping of microsatellite markers for European hazelnut (Corylus avellana L.) from enriched genomic libraries and usefulness in genetic diversity studies. Tree Genet. Genomes 6:513-531, doi: 10.1007/s11295-010-0269-y.

Hoffman, J.I. and H.J. Nichols. 2011. A novel approach for mining polymorphic microsatellite markers in silico. PLoS One 6:e23283, doi: 10.1371/journal.pone.0023283.

Honig, J.A., M. Muehlbauer, J.M. Capik, C. Kubik, J.N. Vaiciunas, S.A. Mehlenbacher, and T.J. Molnar. 2019. Identification and mapping of eastern filbert blight resistance quantitative trait loci in European hazelnut using double digestion restriction site associated DNA sequencing. J. Amer. Soc. Hort. Sci. 144:1-10, doi: 10.21273/ JASHS04694-19.

Hulbert, S.H., C.A. Webb, S.M. Smith, and Q. Sun. 2001. Resistance gene complexes: Evolution and utilization. Annu. Rev. Phytopathol. 39:285-312, doi: 10.1146/annurev.phyto.39.1.285.

Johnson, K.B., S.A. Mehlenbacher, J.K. Stone, J.W. Pscheidt, and J.N. Pinkerton. 1996. Eastern filbert blight of European hazelnut-It's becoming a manageable disease. Plant Dis. 80:1308-1316, doi: 10.1094/PD-80-1308.

Johnson, K.B., J.N. Pinkerton, S.M. Gaudreault, and J.K. Stone. 1994. Infection of European hazelnut by Anisogramma anomala: Site of infection and effect of host developmental stage. Phytopathology 84: 1465-1470, doi: 10.1094/Phyto-84-1465.

Kalinowski, S.T. and M.L. Taper. 2006. Maximum likelihood estimation of the frequency of null alleles at microsatellite loci. Conserv. Genet. 7:991-995, doi: 10.1007/s10592-006-9134-9.

Khodaeiaminjan, M., S. Kafkas, E. Ziya Motalebipour, and N. Çoban. 2018. In silico polymorphic novel SSR marker development and the 
first SSR-based genetic linkage map in pistachio. Tree Genet. Genomes 14(45), doi: 10.1007/s11295-018-1259-8.

Komaei Koma, G. 2020. High-density linkage maps for european hazelnut (Corylus avellana L.) from single nucleotide polymorphism markers and mapping new sources of resistance to eastern filbert blight. PhD Diss., Oregon State Univ., Corvallis.

Leadbetter, C.W., J.M. Capik, S.A. Mehlenbacher, and T.J. Molnar. 2016. Hazelnut accessions from Russia and Crimea transmit resistance to eastern filbert blight. J. Am. Pomol. Soc. 70:92-109.

Li, H., B. Handsaker, A. Wysoker, T. Fennell, J. Ruan, N. Homer, G. Marth, G. Abecasis, R. Durbin; and 1000 Genome Project Data Processing Subgroup. 2009. The Sequence Alignment/Map format and SAMtools. Bioinformatics 25:2078-2079, doi: 10.1093/bioinformatics/btp352.

Liu, K. and S.V. Muse. 2005. PowerMarker: An integrated analysis environment for genetic marker analysis. Bioinformatics 21:2128 2129, doi: 10.1093/bioinformatics/bti282.

Lunde, C.F., S.A. Mehlenbacher, and D.C. Smith. 2000. Survey of hazelnut cultivars for response to eastern filbert blight inoculation. HortScience 35:729-731, doi: 10.21273/HORTSCI.35.4.729.

Lunde, C.F., S.A. Mehlenbacher, and D.C. Smith. 2006. Segregation for resistance to eastern filbert blight in progeny of 'Zimmerman' hazelnut. J. Amer. Soc. Hort. Sci. 131:731-737, doi: 10.21273/JASHS. 131.6.731.

McHale, L., X. Tan, P. Koehl, and R.W. Michelmore. 2006. Plant NBS-LRR proteins: Adaptable guards. Genome Biol. 7(212), doi: 10.1186/gb-2006-7-4-212.

Mehlenbacher, S.A. 1995. Classical and molecular approaches to breeding fruit and nut crops for disease resistance. HortScience 30:466-477.

Mehlenbacher, S.A. and G. Bhattarai. 2018. An updated linkage map for hazelnut with new simple sequence repeat markers. Acta Hort. 1226:31-37, doi: 10.17660/ActaHortic.2018.1226.4.

Mehlenbacher, S.A., R.N. Brown, E.R. Nouhra, T. Gökirmak, N.V. Bassil, and T.L. Kubisiak. 2006. A genetic linkage map for hazelnut (Corylus avellana L.) based on RAPD and SSR markers. Genome 49:122-133, doi: 10.1139/g05-091.

Mehlenbacher, S.A. and D.C. Smith. 2004. Hazelnut pollenizers 'Gamma', 'Delta', 'Epsilon', and 'Zeta'. HortScience 39:14981499, doi: 10.21273/Hortsci.39.6.1498.

Mehlenbacher, S.A., D.C. Smith, and R. McCluskey. 2009. 'Yamhill' hazelnut. HortScience 44:845-847, doi: 10.21273/HORTSCI.44.3.845.

Mehlenbacher, S.A., D.C. Smith, and R. McCluskey. 2011. 'Jefferson' hazelnut. HortScience 46:662-664, doi: 10.21273/HORTSCI.46.4.662.

Mehlenbacher, S.A., D.C. Smith, and R. McCluskey. 2012. 'Eta' and 'Theta' hazelnut pollenizers. HortScience 47:1180-1181, doi: 10.21273/ HORTSCI.47.8.1180.

Mehlenbacher, S.A., D.C. Smith, and R.L. McCluskey. 2013. 'Dorris' hazelnut. HortScience 48:796-799, doi: 10.21273/HORTSCI.48. 6.796.

Mehlenbacher, S.A., D.C. Smith, and R. McCluskey. 2014. 'Wepster' hazelnut. HortScience 49:346-349, doi: 10.21273/HORTSCI.49.3.346.

Mehlenbacher, S.A., D.C. Smith, and R.L. McCluskey. 2016. 'McDonald' hazelnut. HortScience 51:757-760, doi: 10.21273/ HORTSCI.51.6.757.

Mehlenbacher, S.A., D.C. Smith, and R.L. McCluskey. 2018. 'York' and 'Felix' hazelnut pollenizers. HortScience 53:904-910, doi: 10.21273/HORTSCI12836-18

Mehlenbacher, S.A., D.C. Smith, and R.L. McCluskey. 2019. 'PollyO' hazelnut. HortScience 54:1429-1432, doi: 10.21273/HORTSCI14089-19.

Mehlenbacher, S.A., M.M. Thompson, and H.R. Cameron. 1991. Occurrence and inheritance of resistance to eastern filbert blight in 'Gasaway' hazelnut. HortScience 26:410-411, doi: 10.21273/ HORTSCI.26.4.410

Milne, I., M. Bayer, L. Cardle, P. Shaw, G. Stephen, F. Wright, and D. Marshall. 2010. Tablet-Next generation sequence assembly visualization. Bioinformatics 26:401-402, doi: 10.1093/bioinformatics/btp666.
Molnar, T.J., J. Capik, S. Zhao, and N. Zhang. 2010a. First report of eastern filbert blight on Corylus avellana 'Gasaway' and 'VR20-11' caused by Anisogramma anomala in New Jersey. Plant Dis. 94: 1265, doi: 10.1094/PDIS-06-10-0445.

Molnar, T.J., J.C. Goffreda, and C.R. Funk. 2010b. Survey of Corylus resistance to Anisogramma anomala from different geographic locations. HortScience 45:832-836, doi: 10.21273/HORTSCI.45.5.832.

Molnar, T.J., D.E. Zaurov, J.C. Goffreda, and S.A. Mehlenbacher. 2007. Survey of hazelnut germplasm from Russia and Crimea for response to eastern filbert blight. HortScience 42:51-56, doi: 10.21273/HORTSCI.42.1.51

Muehlbauer, M., J. Honig, J.M. Capik, J.N. Vaiciunas, and T. Molnar. 2014. Characterization of eastern filbert blight-resistant hazelnut germplasm using microsatellite markers. J. Amer. Soc. Hort. Sci. 139:399-432, doi: 10.21273/JASHS.139.4.399.

Pinkerton, J.N., K.B. Johnson, S.A. Mehlenbacher, and J.W. Pscheidt. 1993. Susceptibility of European hazelnut clones to eastern filbert blight. Plant Dis. 77:261-266, doi: 10.1094/PD-77-0261.

Pinkerton, J.N., K.B. Johnson, J.K. Stone, and K.L. Ivors. 1998. Maturation and seasonal discharge pattern of ascospores of Anisogramma anomala. Phytopathology 88:1165-1173, doi: 10.1094/phyto.1998.88.11.1165.

Pinkerton, J.N., K.B. Johnson, D.E. Aylor, and J.K. Stone. 2001. Spatial and temporal increase of eastern filbert blight in European hazelnut orchards in the Pacific Northwest. Phytopathology 91:12141223, doi: 10.1094/phyto.2001.91.12.1214.

Pinkerton, J.N., K.B. Johnson, K.M. Theiling, and J.A. Griesbach. 1992. Distribution and characteristics of the eastern filbert blight epidemic in western Oregon. Plant Dis. 76:1179-1182, doi: 10.1094/Pd-76-1179.

Pinkerton, J.N., J.K. Stone, S.J. Nelson, and K.B. Johnson. 1995. Infection of european hazelnut by Anisogramma anomala-Ascospore adhesion, mode of penetration of immature shoots, and host response. Phytopathology 85:1260-1268, doi: 10.1094/Phyto-85-1260.

Pscheidt, J.W. 2010. Eastern filbert blight help page. 10 May 2019. $<$ http://oregonstate.edu/dept/botany/epp/EFB/index.htm $>$.

Pscheidt, J.W. and C.M. Ocamb (eds.). 2020. Hazelnut (Corylus avellana) - eastern filbert blight. Pacific Northwest plant disease management handbook. 20 Nov. 2020. <https://pnwhandbooks.org/ plantdisease $>$.

Ramalhosa, E., T. Delgado, L. Estevinho, and J.A. Pereira. 2011. Chapter 73, Hazelnut (Corylus avellana L.) cultivars and antimicrobial activity, p. 627-636. In: V.R. Preedy, R.R. Watson, and V.B. Patel (eds.). Nuts and seeds in health and disease prevention. Academic Press, San Diego, CA, doi: 10.1016/B978-0-12-375688-6.10073-8.

Rowley, E.R., R. VanBuren, D.W. Bryant, H.D. Priest, S.A. Mehlenbacher, and T.C. Mockler. 2018. A draft genome and high-density genetic map of European hazelnut (Corylus avellana L.). bioRxiv: 469015, doi: 10.1101/469015.

Salesses, G. 1973. Etude cytologique du genre Corylus. mise en evidence d'une translocation hétérozygote chez quelques variétés de noisetier cultivé $(C$. avellana), à fertilité pollinique réduite. Ann. Amelior. Plant. 23(1):59-66.

Salesses, G. and A. Bonnet. 1988. Etude cytogénétique d'hybrides entre variétés de noisetier (Corylus avellana) porteuses d'une translocation à l'état hétérozygote. Cytologia 53:407-413.

Sathuvalli, V.R., S.A. Mehlenbacher, and D.C. Smith. 2010. Response of hazelnut accessions to greenhouse inoculation with Anisogramma anomala. HortScience 45:1116-1119, doi: 10.21273/HORTSCI. 45.7.1116.

Sathuvalli, V.R., H. Chen, S.A. Mehlenbacher, and D.C. Smith. 2011a. DNA markers linked to eastern filbert blight resistance in 'Ratoli' hazelnut (Corylus avellana L.). Tree Genet. Genomes 7: 337-345, doi: 10.1007/s11295-010-0335-5.

Sathuvalli, V.R., S.A. Mehlenbacher, and D.C. Smith. 2011b. DNA markers linked to eastern filbert blight resistance from a hazelnut selection from the Republic of Georgia. J. Amer. Soc. Hort. Sci. 136: 350-357, doi: 10.21273/JASHS.136.5.350. 
Sathuvalli, V.R., S. Mehlenbacher, and D.C. Smith. 2012. Identification and mapping of DNA markers linked to eastern filbert blight resistance from OSU 408.040 hazelnut. HortScience 47:570-573, doi: 10.21273/HORTSCI.47.5.570.

Sathuvalli, V.R., S.A. Mehlenbacher, and D.C. Smith. 2017. High-resolution genetic and physical mapping of the eastern filbert blight resistance region in 'Jefferson' hazelnut (Corylus avellana L.). Plant Genome 10(2):1-10, doi: 10.3835/plantgenome2016.12.0123.

Shirasawa, K., P. Koilkonda, K. Aoki, H. Hirakawa, S. Tabata, M. Watanabe, M. Hasegawa, H. Kiyoshima, S. Suzuki, C. Kuwata, Y. Naito, T. Kuboyama, A. Nakaya, S. Sasamoto, A. Watanabe, M. Kato, K. Kawashima, Y. Kishida, M. Kohara, A. Kurabayashi, C. Takahashi, H. Tsuruoka, T. Wada, and S. Isobe. 2012. In silico polymorphism analysis for the development of simple sequence repeat and transposon markers and construction of linkage map in cultivated peanut. BMC Plant Biol. 12(80), doi: 10.1186/1471-2229-12-80.

Snelling, J.W., V.R. Sathuvalli, B.C. Colburn, G. Bhattarai, E.R. Rowley, T.C. Mockler, C.A. Saski, D. Copetti, and S.A. Mehlenbacher. 2018. Genomic resource development in hazelnut breeding. Acta Hort. 1226:39-45, doi: 10.17660/ActaHortic.2018.1226.5.

Stone, J.K., K.B. Johnson, J.N. Pinkerton, and J.W. Pscheidt. 1992. Natural infection period and susceptibility of vegetative seedlings of European hazelnut to Anisogramma anomala. Plant Dis. 76:348-352, doi: 10.1094/pd-76-0348.

Tang, J., S.J. Baldwin, J.M. Jacobs, C.G.d. Linden, R.E. Voorrips, J.A. Leunissen, H. van Eck, and B. Vosman. 2008. Large-scale identification of polymorphic microsatellites using an in silico approach. BMC Bioinformatics 9(374), doi: 10.1186/1471-2105-9-374.
Thompson, J.D., T.J. Gibson, and D.G. Higgins. 2002. Multiple sequence alignment using ClustalW and ClustalX. Curr. Protoc. Bioinformatics, doi: 10.1002/0471250953.bi0203s00.

Untergasser, A., I. Cutcutache, T. Koressaar, J. Ye, B.C. Faircloth, M. Remm, and S.G. Rozen. 2012. Primer3-New capabilities and interfaces. Nucleic Acids Res. 40(15):e115, doi: 10.1093/nar/ gks596.

U.S. Department of Agriculture-National Agricultural Statistics Service. 2018. Data and statistics. 5 May 2019. <https://www.nass.usda. gov/Data_and_Statistics/index.php $>$.

Vukosavljev, M., G.D. Esselink, W.P.C. van 't Westende, P. Cox, R.G.F. Visser, P. Arens, and M.J.M. Smulders. 2015. Efficient development of highly polymorphic microsatellite markers based on polymorphic repeats in transcriptome sequences of multiple individuals. Mol. Ecol. Resour. 15:17-27, doi: 10.1111/17550998.12289.

Wang, X., P. Lu, and Z. Luo. 2013. GMATo: A novel tool for the identification and analysis of microsatellites in large genomes. Bioinformation 9:541-544, doi: 10.6026/97320630009541.

Ye, J., S. McGinnis, and T.L. Madden. 2006. BLAST: Improvements for better sequence analysis. Nucleic Acids Res. 34(supplement 2): W6-W9, doi: 10.1093/nar/gkl164.

Zhang, J., G.D. Esselink, D. Che, M. Fougère-Danezan, P. Arens, and M.J.M. Smulders. 2013. The diploid origins of allopolyploid rose species studied using single nucleotide polymorphism haplotypes flanking a microsatellite repeat. J. Hort. Sci. Biotechnol. 88:85-92, doi: 10.1080/14620316.2013. 11512940 . 
Supplemental Table 1. Pedigrees of seven hazelnut progenies segregating for resistance to eastern filbert blight. Resistant selections are underlined; all others are susceptible.

$10015=$ OSU $1187.101 \times$ OSU 1155.049

OSU 1187.101 from seeds purchased in Holmskij, Russia (RUS- \#2)

OSU $1155.049=$ OSU $517.030 \times$ OSU 556.046

OSU $517.030=$ OSU $255.003 \times$ Tonda di Giffoni

OSU $255.003=$ OSU $43.098 \times$ Casina

OSU $43.098=$ Montebello $\mathrm{x}$ Casina

OSU 556.046 = Römische Nuss x OSU 54.039

OSU 54.039 from seeds collected in Giresun, Turkey

$11024=$ OSU $814.073 \times \underline{\text { Moscow \#2 }}$

OSU 814.073 = OSU 486.001 $\times$ Tonda Pacifica

OSU $486.001=$ OSU $225.077 \times$ Brixnut

OSU $225.077=$ Tombul Ghiaghli $x$ OSU 42.103

OSU $42.103=$ Montebello $\mathrm{x}$ Compton

$12030=$ OSU $1269.020 \times \underline{\text { Moscow \#27 }}$

OSU $1269.020=$ OSU $593.071 \times$ OSU 806.021

OSU 593.071 $=$ Segorbe $\mathrm{x}$ OSU 265.139

OSU $265.139=$ Tombul (Extra Ghiaghli) $x$ Willamette

OSU 806.021 = Waterloo $x$ OSU 384.095

OSU $384.095=$ Casina $x$ OSU 55.129

OSU 55.129 = Tonda Gentile delle Langhe $\mathrm{x}$ Tombul (Extra Ghiaghli)

$13030=$ OSU $1166.123 \times$ OSU 1235.078

OSU 1166.123 from seeds collected in Sochi, Russia

OSU $1235.078=$ OSU 539.031 x OSU 772.046

OSU 539.031 = OSU $275.031 \times$ Sant Pere

OSU 275.031 $=$ Montebello $x$ OSU 74.37

OSU $74.037=14.084 \times$ OSU 17.068

OSU $14.084=$ Barcelona $x$ Daviana

OSU $17.068=$ Barcelona $x$ Tombul Ghiaghli

OSU $772.046=$ OSU $444.067 \times$ OSU 383.087

OSU $444.067=$ Willamette $\mathrm{x}$ OSU 54.021

OSU 54.021 from seeds collected in Giresun, Turkey

OSU $387.087=$ Casina $x$ OSU 55.129

OSU 55.129 = Tonda Gentile delle Langhe $\mathrm{x}$ Tombul (Extra Ghiaghli)

$13031=\underline{\text { OSU } 1166.123} \times$ OSU 1236.134

OSU $1236.134=$ OSU $593.071 \times$ OSU 776.095

OSU 593.071 $=$ Segorbe $\times 265.139$

OSU 265.139 = Tombul (Extra Ghiaghli) x Willamette

OSU 776.095 = Tonda Pacifica $x$ OSU 443.129

OSU $443.129=$ OSU $183.060 \times$ OSU 54.056

OSU $183.060=$ Montebello $x$ OSU 14.084

OSU 14.084 = Barcelona $x$ Daviana

OSU 54.056 from seeds collected in Giresun, Turkey

$14031=$ Sacajawea $\mathrm{x}$ Rutgers H3R07P11

Rutgers H3R07P11 from seeds purchased from a roadside vendor near Simferopol, Crimea

$14035=$ Rutgers H3R12P62 $\times$ OSU 1378.046

Rutgers H3R12P62 from seeds purchased from a roadside vendor near Simferopol, Crimea OSU $1378.046=$ OSU $943.020 \times$ OSU 885.056

OSU $943.020=$ OSU $617.015 \times$ OSU 495.045

OSU $617.015=$ OSU $311.046 \times$ Clark

OSU $311.046=$ OSU 23.017 x Tonda Gentile delle Langhe

OSU 23.017 = Barcelona x Tombul (Extra Ghiaghli)

OSU 495.045 from seeds received from southern Russia

OSU $885.056=$ OSU $539.044 \times$ Tonda Pacifica

OSU $539.044=$ OSU $275.031 \times$ Sant Pere

OSU 275.031 = Montebello $x$ OSU 74.37

OSU $74.037=14.084 \times$ OSU 17.068

OSU $14.084=$ Barcelona $x$ Daviana

OSU $17.068=$ Barcelona $x$ Tombul Ghiaghli 
Supplemental Table 2. Primer sequences of 45 polymorphic simple sequence repeat markers in hazelnut.

\begin{tabular}{|c|c|c|c|c|}
\hline \multirow[b]{2}{*}{ Marker } & \multirow[b]{2}{*}{$\mathrm{LG}^{2}$} & \multicolumn{2}{|c|}{ Primer sequence } & \multirow[b]{2}{*}{ Size (bp) } \\
\hline & & Forward & Reverse & \\
\hline MS0026.03 & 2 & TACCGTCGGAAAGCTGACTC & CGTGCCAAACATACAAGCAG & 295 \\
\hline MS0026.04 & 2 & TGAGCCAACAGAGTTCCCTA & TTTCAGCCCTTCCGATAGAG & 206 \\
\hline MS0026.07 & 2 & СTTTTTCTCCCTGGGTCCAT & ATCCCAATTCCTGCATCAAC & 287 \\
\hline MS0026.08 & 2 & TAACCAAACGGGTGGAGAGA & TGCCTTTGATTTTCCGATCT & 288 \\
\hline MS0026.10 & 2 & TTAACATGCTGCTCCGACAA & GTATGCGGCTGCTGTATGGT & 257 \\
\hline MS0026.11 & 2 & TTAACTGAACCGAGCCGAAC & TAAGCCACCGGACATGGTAG & 295 \\
\hline MS0026.13 & 2 & CCСТTTCAAACACCCATTTG & TTCATGGTGTAAAGCCGAGA & 261 \\
\hline MS0026.14 & 2 & GGTCTGTTTGATTTCGAGCAA & AAATGGGCTTTGAGTCATGG & 262 \\
\hline MS0107.02 & 2 & TGCTTGTGAACGACTCAATACA & TGCAGCCTAAAGTCCTTTTCC & 172 \\
\hline MS0107.03 & 2 & CACACGCAATTCTCACCATT & CCTGCATAGGAATCCCCTTT & 209 \\
\hline MS0107.05 & 2 & GTGGGCATCAGATCACAAAA & TCGACCTGGAAGAGATGACC & 207 \\
\hline MS0113.01 & 2 & TСССТСАСССАССАТTTTTА & CCTTCGCAAAATCACAAACA & 287 \\
\hline MS0113.02 & 2 & TGGGATTTCCACCCTATCAG & CACTTTTAACTGACGGAATGAGA & 271 \\
\hline MS0113.03 & 2 & СCCCCTATTTTGCCATTTTT & TGCCTGAAAAACTCTGCATTT & 210 \\
\hline MS0113.04 & 2 & ССАСТCCTTCTTGCTTTGCT & СTTCTGCCGCTAGAGTGCTT & 214 \\
\hline MS0113.06 & 2 & TCAGGCAATCAAGTGGGTTA & AAGAGGTTTTCGGTTCACCA & 315 \\
\hline MS0121.02 & 2 & AAGCAAAGAAAGGGCGAGAT & AGGACTCCAAAGCGTGGAT & 272 \\
\hline MS0121.04 & 2 & CAAGATGGCCTGCAATAAGC & CTGCCGGATCTCTCTCTCTC & 255 \\
\hline MS0140.02 & 2 & AAACTGAGCAAACCCCACAA & TGCGTCAGGCTGTAGTTGTT & 264 \\
\hline MS0140.04 & 2 & GGAGTTGCTTGCGTAACTGG & СТСТСССТСААСССААТСAG & 136 \\
\hline MS0140.05 & 2 & TCTGCTCTGGCTTGGCTAAA & AAGCAAAAACACGAGGGAAA & 285 \\
\hline MS0229.02 & 2 & AGAAACAATGCAATTCCCAGA & TGTACGGAGATGACAAGAGGTG & 285 \\
\hline MS0230.01 & 2 & CCGAGTACATCTCCATGCAA & СССТТСТССССАСТTТТСТТ & 209 \\
\hline MS0230.03 & 2 & CCATCACCCAGATCAAATCC & ACCCTCACAGCACAGCTACC & 263 \\
\hline MS0284.01 & 2 & GATCAAATCCCACACCAAGC & AAGAAGCAAACCCTCACAGC & 258 \\
\hline MS0046.01 & 7 & CAGTCGAGGACCCATCTCTC & GGGGCTTATCAGATTGCTGT & 29 \\
\hline MS0046.02 & 7 & GAAAACGATCCCTCTCGTCA & GGTCCGAGGATCAGGAATTT & 188 \\
\hline MS0046.07 & 7 & AGGCAAAATGCACATCACAA & CCAAGGAACGAAAGCAAGAG & 14 \\
\hline MS0061.02 & 7 & TCACATCATCACCTCCAAAGTC & GGAGAGGAGGAGACCAAAGAA & 183 \\
\hline MS0061.03 & 7 & CCCAGGTCTCTCCСTCTCTC & TGCCTTTTGTGTCCAATGAA & 92 \\
\hline MS0061.04 & 7 & GTTGTGGTGCCAAAGAATCC & AGCAAAATCCССTTСTCTCC & \\
\hline MS0061.05 & 7 & GCACTACGTCACCCACTTCA & TTGTTGCACAGGAGAGATGG & \\
\hline MS0076.03 & 7 & GAGCCGACACCTTCTTAGGC & TGACCCAAATCCCTTCTCAA & \\
\hline MS0076.04 & 7 & AACCATTTCTCGAAGCAAGC & GCTAGCGGTTACCCATGTTC & \\
\hline MS0076.08 & 7 & AGAGCAAGAGCAACGGAGAG & CGGGTTGCGGGTATAAGAAT & \\
\hline MS0126.04 & 7 & CCGGAAAATAGGGCACTTCT & CCTGGCAAGATGACCAGTTT & \\
\hline MS0170.02 & 7 & CCAGGACACAAATCTCAAACC & GCACCAGAGCTTTTTGAATGG & \\
\hline MS0074.02 & 10 & CCCACAAATTCAGCTTGGAG & CGGTGGAGGAGTTGATGAGT & \\
\hline MS0074.03 & 10 & AACACCCATGTAAGCCAACTG & GCAAGTGTTCTGCCCATTTC & \\
\hline MS0074.06 & 10 & TCTGCCACAACATTGAAAGC & CTCTCGACGTTCTTGGTGGT & \\
\hline MS0074.08 & 10 & GCCCAAACCAATTTCACACT & GCCTCAGCACGTACCTCTTC & \\
\hline MS0294.03 & 3 & CCСATCAAAATTCCСАТАCC & TGTTGCTTCACATCATTCCAA & 207 \\
\hline MS0535.01 & 10 & GCGTCAAAATCGCTCTCTCT & GCCACCCCGAGTAAGAATTA & \\
\hline
\end{tabular}

${ }^{z}$ Linkage group based on genetic mapping and scaffold in the 'Jefferson' genome sequence (V3).

${ }^{y}$ Expected size based on the contig sequence in the 'Jefferson genome (V2) used for primer design. 


\begin{tabular}{|c|c|c|c|c|c|c|c|}
\hline \multirow{3}{*}{$\frac{\mathrm{LG}}{2}$} & \multirow{3}{*}{$\begin{array}{l}\text { Marker } \\
\text { MS0230.03 }\end{array}$} & \multicolumn{3}{|c|}{ Coordinates (V2) } & \multicolumn{3}{|c|}{ Coordinates (V3) } \\
\hline & & \multicolumn{3}{|c|}{ Contig Start End } & \multicolumn{2}{|c|}{ Scaffold } & \multirow{2}{*}{$\frac{\text { End }}{47542}$} \\
\hline & & 230 & 481968 & 482499 & 1 & 47010 & \\
\hline 2 & MS0230.01 & 230 & 44477 & 45006 & 1 & 484503 & 485033 \\
\hline 2 & GB722 & & & & 1 & 807056 & 807585 \\
\hline 2 & MS0284.01 & 284 & 20442 & 20963 & 1 & 877686 & 878208 \\
\hline 2 & MS0229.02 & 229 & 81021 & 81544 & 1 & 1402327 & 1402851 \\
\hline 2 & MS0107.05 & 107 & 639095 & 639616 & 1 & 2467432 & 2467954 \\
\hline 2 & MS0107.03 & 107 & 373893 & 374424 & 1 & 2732624 & 2733156 \\
\hline 2 & MS0107.02 & 107 & 243481 & 244016 & 1 & 2863032 & 2863568 \\
\hline 2 & MS0140.05 & 140 & 724995 & 725520 & 1 & 3922023 & 3922533 \\
\hline 2 & MS0140.04 & 140 & 545159 & 545698 & 1 & 4360840 & 4361380 \\
\hline 2 & MS0140.02 & 140 & 210151 & 210678 & 1 & 4695860 & 4696388 \\
\hline 2 & MS0026.03 & 26 & 530036 & 530567 & 1 & 6191882 & 6192414 \\
\hline 2 & MS0026.04 & 26 & 739774 & 740309 & 1 & 6401620 & 6402156 \\
\hline 2 & MS0026.07 & 26 & 1311185 & 1311706 & 1 & 6973031 & 6973553 \\
\hline 2 & MS0026.08 & 26 & 1526448 & 1526981 & 1 & 7188294 & 7188828 \\
\hline 2 & MS0026.10 & 26 & 1909574 & 1910093 & 1 & 7571420 & 7571940 \\
\hline 2 & MS0026.11 & 26 & 2151015 & 2151544 & 1 & 7812861 & 7813391 \\
\hline 2 & MS0026.13 & 26 & 2507884 & 2508417 & 1 & 8169730 & 8170264 \\
\hline 2 & MS0026.14 & 26 & 2752198 & 2752717 & 1 & 8414044 & 8414564 \\
\hline 2 & GB827 & & & & 1 & 13471867 & 13472343 \\
\hline 2 & MS0113.01 & 113 & 51754 & 52291 & 1 & 15009616 & 15010154 \\
\hline 2 & MS0113.02 & 113 & 259277 & 259798 & 1 & 15217139 & 15217661 \\
\hline 2 & MS0113.03 & 113 & 503338 & 503869 & 1 & 15461200 & 15461732 \\
\hline 2 & B501 & & & & 1 & 15543392 & 15543579 \\
\hline 2 & MS0113.04 & 113 & 658259 & 658790 & 1 & 15616121 & 15616653 \\
\hline 2 & MS0113.06 & 113 & 862705 & 863240 & 1 & 15820567 & 15821103 \\
\hline 2 & B011 & & & & 1 & 16174207 & 16174783 \\
\hline 2 & GB889 & & & & 1 & 16305669 & 16306107 \\
\hline 2 & MS0121.02 & 121 & 274642 & 275173 & 1 & 17076258 & 17076790 \\
\hline 2 & MS0121.04 & 121 & 885620 & 886151 & 1 & 17687236 & 17687768 \\
\hline 7 & GB307 & & & & 7 & 1107239 & 1107929 \\
\hline 7 & MS0170.02 & 170 & 229380 & 229903 & 7 & 1191369 & 1191893 \\
\hline 7 & GB372 & & & & 7 & 1228690 & 1229210 \\
\hline 7 & MS0076.08 & 76 & 1452827 & 1453344 & 7 & 4533752 & 4534270 \\
\hline 7 & GB319 & & & & 7 & 4774917 & 4775312 \\
\hline 7 & MS0076.04 & 76 & 694194 & 694727 & 7 & 5292369 & 5292903 \\
\hline 7 & MS0076.03 & 76 & 469409 & 469932 & 7 & 5517164 & 5517688 \\
\hline 7 & GB822 & & & & 7 & 5561744 & 5562253 \\
\hline 7 & B020 & & & & 7 & 5989286 & 5989874 \\
\hline 7 & B753 & & & & 7 & 7146391 & 7146801 \\
\hline 7 & MS0046.07 & 46 & 1435084 & 1435609 & & 7720735 & 7721261 \\
\hline 7 & B733 & & & & 7 & 8051584 & 8051958 \\
\hline 7 & MS0046.02 & 46 & 233137 & 233672 & 7 & 8922672 & 8923208 \\
\hline 7 & MS0046.01 & 46 & 112816 & 113359 & 7 & 9042985 & 9043529 \\
\hline 7 & B751 & & & & 7 & 14541791 & 14542211 \\
\hline 7 & MS0126.04 & 126 & 857591 & 858122 & 7 & 15166514 & 15167046 \\
\hline 7 & MS0061.02 & 61 & 301442 & 301961 & 7 & 16276619 & 16277139 \\
\hline 7 & MS0061.03 & 61 & 556683 & 557206 & 7 & 16531860 & 16532384 \\
\hline 7 & MS0061.04 & 61 & 1202097 & 1202620 & 7 & 17177274 & 17177798 \\
\hline 7 & BR238 & & & & 7 & 17178112 & 17178711 \\
\hline 7 & MS0061.05 & 61 & 1609138 & 1609667 & 7 & 17584315 & 17584845 \\
\hline 7 & KG840 & & & & 7 & 20781605 & 20782387 \\
\hline
\end{tabular}

